\title{
Hydrostatic and non-hydrostatic simulations of dense waters cascading off a shelf: the East Greenland case
}

\author{
Marcello G. Magaldi ${ }^{\mathrm{a}, \mathrm{b}}$, Thomas W. N. Haine ${ }^{\mathrm{b}}$ \\ ${ }^{a}$ Istituto di Scienze Marine, U.O.S. di Pozzuolo di Lerici, \\ Consiglio Nazionale delle Ricerche, Forte Santa Teresa, I-19036, Lerici (SP), Italy \\ ${ }^{b}$ Department of Earth and Planetary Sciences, The Johns Hopkins University, \\ Olin Hall, 34th and North Charles Streets, Baltimore, MD 21218, USA
}

\section{Abstract}

The cascade of dense waters off the Southeast Greenland shelf during summer 2003 is investigated with two very high-resolution $(0.5-\mathrm{km})$ simulations. The first simulation is non-hydrostatic. The second simulation is hydrostatic and about 3.75 times less expensive. Both simulations are compared to a 2-km hydrostatic run, about 31 times less expensive than the $0.5 \mathrm{~km}$ nonhydrostatic case.

Time-averaged volume transport values for deep waters are insensitive to the changes in horizontal resolution and vertical momentum dynamics. By this metric, both lateral stirring and vertical shear instabilities associated with the cascading process are accurately parameterized by the turbulent schemes used at 2-km horizontal resolution. All runs compare well with observations and confirm that the cascade is mainly driven by cyclones which are linked to dense overflow boluses at depth. The passage of the cyclones is also associated with the generation of internal gravity waves (IGWs) near the shelf.

Surface fields and kinetic energy spectra do not differ significantly between 
the runs for horizontal scales $L>30 \mathrm{~km}$. Complex structures emerge and the spectra flatten at scales $L<30 \mathrm{~km}$ in the $0.5-\mathrm{km}$ runs. In the nonhydrostatic case, additional energy is found in the vertical kinetic energy spectra at depth in the $2 \mathrm{~km}<L<10 \mathrm{~km}$ range and with frequencies around 7 times the inertial frequency. This enhancement is missing in both hydrostatic runs and is here argued to be due to the different IGW evolution and propagation offshore. The different IGW behavior in the non-hydrostatic case has strong implications for the energetics: compared to the 2-km case, the baroclinic conversion term and vertical kinetic energy are about 1.4 and at least 34 times larger, respectively. This indicates that the energy transfer from the geostrophic eddy field to IGWs and their propagation away from the continental slope is not properly represented in the hydrostatic runs.

Keywords: Dense water cascading, Non-hydrostatic model, Irminger Sea

\section{Introduction}

The phenomenon of dense waters cascading off coastal shelves takes place in different parts of the world oceans and is documented in more than sixty locations (Ivanov et al., 2004). The dense water cascade plays an important role from an ecological and geological perspective: being associated with large fluxes of suspended particle and organic matter, it represents an effective mechanism for the exchange of phytoplankton, nutrients, sediments and pollutants between shallow coastal regions and the deep ocean (Whitehead, 1987; Canals et al., 2006). From a more dynamical perspective, it is related to deep water formation. In some cases, the relationship is well established: Antarctic Bottom Water is derived from dense shelf waters cascading along 
the Antarctic margins (Gordon et al., 2009; Budillon et al., 2011) and sinking of dense shelf waters contributes to the formation of the deep waters of the Arctic Ocean (Rudels, 1986; Jones et al., 1995). It is also known that dense shelf currents from the North Adriatic Sea are important for the formation of deep waters in the Eastern Mediterranean (Vilibić and Supić, 2005; Mihanović et al., 2013). In other places, like the Gulf of Lions, the Aegean and East Japan Seas, the relationship is often underestimated because it coexists with open-ocean convection (Theocharis and Georgopoulos, 1993; Kim et al., 2008; Durrieu de Madron et al., 2013).

Here, we focus on the waters cascading off the Southeast Greenland shelf, adjacent to the Irminger Basin (Fig. 1a). The case is dynamically important because the cascading process is dominated by a complex interplay between different components of the Basin boundary current system. The surface component is made up of light waters of both Atlantic and Arctic origins which flow next to each other and form the strong Irminger Current/East Greenland Current front (see schematic in Fig. 1a). The component at depth consists of denser Nordic Seas $\left(\sigma_{\theta} \geq 27.8 \mathrm{~kg} \mathrm{~m}^{-3} ; \sigma_{\theta}\right.$ is the potential density anomaly referenced to the surface) waters which overflow from the Denmark Strait sill in the Denmark Strait Overflow (DSO). The DSO transport has been measured for 25 years. For periods longer than a few months the average DSO volume transport through the sill is approximately $3 \mathrm{~Sv}(1 \mathrm{~Sv}$ $\equiv 10^{6} \mathrm{~m}^{3} \mathrm{~s}^{-1}$ ) to the south (Saunders, 2001; Macrander et al., 2007; Dickson et al., 2008; Jochumsen et al., 2012). For shorter time scales, the transport exhibits strong fluctuations due to flooding events which last $1-2$ days and are followed by slack periods (Ross, 1977; Girton et al., 2001; Haine, 2010). 
Boluses of dense Denmark Strait Overflow waters (DSOW) move toward the deeper parts of the basin and induce large cyclones via vortex-stretching (Griffiths, 1983; Whitehead et al., 1990; Spall and Price, 1998; Käse et al., 2003; von Appen et al., 2014b). Previous high-resolution numerical simulations (Magaldi et al. 2011, hereinafter MHP11) have showed that the primary triggering mechanism for the cascade off the East Greenland shelf is the passage of these DSO-induced cyclones (see panels and schematic in Fig. 2). This has been also recently confirmed by observations (Harden et al., 2014; von Appen et al., 2014b). The cascade off the East Greenland shelf can be also induced by other mechanisms, like local (Pickart et al., 2005) and nonlocal winds (Harden et al., 2014), or isolated local instabilities (MHP11).

There are two other reasons to focus on the East Greenland shelf. First, recent observations show that only a portion of the $\sigma_{\theta} \geq 27.8 \mathrm{~kg} \mathrm{~m}^{-3}$ waters pass through the Denmark Strait sill. A non-negligible fraction remains on the shelf, shoreward of the $400 \mathrm{~m}$ isobath (Våge et al., 2011; von Appen et al., 2014a). Dense waters cascading off the East Greenland shelfbreak may thus represent an important alternative pathway for Arctic dense waters to reach the Irminger Basin without passing through the sill (Koszalka et al., 2013). Second, the cascade is associated with a recently-discovered energetic feature of the Basin boundary current system: the East Greenland Spill Jet (Pickart et al., 2005). At a section located about $300 \mathrm{~km}$ downstream of the sill (the Spill Jet line, see Fig. 1a), the Spill Jet and DSO waters have comparable transports (MHP11; Brearley et al. 2012). Therefore, the cascade of dense waters off the East Greenland shelf and the resulting Spill Jet represent key processes through which Atlantic and Arctic waters mix (Falina et al., 2012; 
Koszalka et al., 2013).

Despite their importance, simulating dense water cascades in regional models still represents a challenge. The first complication arises from the relatively poor horizontal resolution of current regional models, which have typical horizontal grid spacings of a few kilometers. Dense water cascades are a type of gravity current (Shapiro et al., 2003) which entrain and mix with ambient fluid via turbulent Kelvin-Helmholtz-like instabilities. Due to the difference in scales, their explicit representation in regional models is computationally prohibitive at the present time. The second complication is the omission of non-hydrostatic dynamics, because almost all regional models are based on the hydrostatic approximation to the vertical momentum equation. Vertical acceleration terms are neglected and vertical mixing processes important for gravity currents are thus misrepresented (Özgökmen et al., 2004).

Idealized studies of frontal convective plumes indicate the effects of omitting non-hydrostatic accelerations: The hydrostatic approximation gives too strong vertical velocities (Haine and Williams, 2002). Entrainment, mixing and down-slope descent also depend on non-hydrostatic dynamics in other idealized configurations (Legg et al., 2006).

In this paper, we address the effect of non-hydrostatic dynamics and horizontal resolution on a cascading flow in a realistic configuration where the cascading depends on the passage of the DSO cyclones. Non-hydrostatic dynamics could be crucial in an area where strong vertical velocities are associated with cyclones (see panels (d)-(f) of, and schematic in, Fig. 2). The increase in horizontal resolution is also expected to better resolve the 
dynamics of the narrow East Greenland Spill Jet and the strong gradients between Atlantic and Arctic waters.

We consider the MHP11 $(\sim 2 \mathrm{~km})$ model results and two new very-high resolution $(\sim 0.5 \mathrm{~km})$ simulations, one hydrostatic and one non-hydrostatic. These new simulations are, to our knowledge, the finest and most detailed realistic runs in the area to date. The MHP11 model results agree well with the measurements of DSO volume transport at the sill. When the number of vertical levels is increased to 210 , for a minimum model vertical resolution of $15 \mathrm{~m}$, no significant difference for DSO or Spill Jet volume transports is found (Koszalka et al., 2013). Therefore, the main questions we address in this study are: a) Are the flow characteristics similar in the three runs? b) Are the volume transports for Spill Jet and DSOW sensitive to horizontal resolution and dynamics? The underlying main questions can also be posed in a different way: c) How robust are the 2-km volume transport values calculated at the Spill Jet line? d) Are even finer resolutions and better dynamics needed for accurate estimates of volume transports in a flow where variability is dominated by the cascading process? e) Do the non-hydrostatic dynamics matter (quantitatively and qualitatively) for the Spill Jet formation processes? f) Is the resolution of the $2-\mathrm{km}$ simulation sufficient to accurately simulate the physical processes important for the Spill Jet formation? These are important questions as they inevitably deal with computational costs and feasibility.

The paper is organized as follows. In section 2, the numerical setups for all simulations are explained. Results and differences between runs are quantified in section 3. We compare volume fluxes, vertical sections of velocity 
fields, baroclinic conversion terms at the Spill Jet line and the surface flow evolution, tracer fields and kinetic energy spectra. Results are discussed in section 4 , and conclusions are drawn in section 5 .

\section{Methods}

The MIT general circulation model (MITgcm, Marshall et al., 1997) is run on two numerical grids for the period between June 1 and September 1, 2003. A parent grid is employed for a first simulation, denoted $P$. The parent simulation is the same as in MHP11 and covers the whole domain shown in Fig. 1a for a total of $540 \times 360$ points. On this parent grid, the MITgcm is used in its hydrostatic configuration as already described in MHP11: The mesh is telescopic and reaches a nominal resolution of $2 \mathrm{~km}$ in the area of the Denmark Strait and the Irminger Basin. Open boundary conditions are obtained from the $1 / 12^{\circ}$ North Atlantic non-tidal experiment of the HYbrid Coordinate Ocean Model (Bleck, 2002; Halliwell, 2004; Chassignet et al., 2003, 2007, 2009). The interior MITgcm fields are nudged to the HYCOM boundary values within 20 points of the grid edge. The nudging time scale is 1 day at the boundaries and linearly increases toward the interior to reach the maximum value of 10 days. The zero gradient condition (see Chapman, 1985) is used for the sea surface height while normal velocities are imposed in order to ensure no net inflow. Initial conditions are derived by the process detailed in MHP11: A spin up run begins with a long term average of hydrographic data from the International Council for the Exploration of the Sea database (ICES, see http://www.ices.dk/ocean/) and lasts for 17 months.

A finer child grid consisting of $725 \times 605$ points is nested in the parent 
$P$ grid and is employed for other two simulations. The child grid covers the area around the Spill Jet line (Fig. 1) and has a nominal uniform resolution of $0.5 \mathrm{~km}$ (horizontal refinement ratio of $4: 1$ ). It does not include the Denmark Strait because DSO transport time series at the sill and cyclone characteristics compare well with observations already at 2-km resolution, as shown in MHP11. No radiation conditions are used and the child fields are nudged to the parent values within 20 points of the child grid edge. This one-way nudging works the same as for the parent grid and the HYCOM fields. The lower panels of Fig. 1a show the entire domain of the child grid, including the nudging region. The first child simulation is aimed at exploring differences when the horizontal resolution is varied. It is hydrostatic and denoted $C_{h}$. The second child simulation is configured as $C_{h}$ but aimed at exploring differences when non-hydrostatic dynamics are active. It is thus denoted $C_{n}$.

Other features for the numerical setup are common to all three simulations: The model is run with the non-linear free surface and partial step topography formulation (Adcroft et al., 1997; Campin et al., 2004). The equation of state is due to Jackett and McDougall (1995) while advection for tracers is computed via a third-order direct space-time flux limited scheme with zero explicit diffusivity. The KPP parametrization (Large et al., 1994) is used with a background vertical viscosity of $\nu_{V}=10^{-5} \mathrm{~m}^{2} \mathrm{~s}^{-1}$, while the Leith biharmonic viscosity (Leith, 1967, 1996) is used in the horizontal. The bathymetry is interpolated from the $2 \mathrm{~km}$ resolution International Bathymetric Chart of the Arctic Ocean (IBCAO, Jakobsson et al., 2008). The vertical dimension is discretized by 97 levels with $2 \mathrm{~m}$ resolution at the surface and 
$200 \mathrm{~m}$ resolution at $3300 \mathrm{~m}$ for all simulations (no vertical refinement for the child grid). The vertical resolution along the continental slope where the cascading happens and the Spill Jet resides is $20 \mathrm{~m}$. No-slip conditions are applied to all material boundaries.

Air-sea fluxes are calculated within the model using the 6-hourly global National Center for Environmental Prediction (NCEP) Reanalysis data (Kalnay et al., 1996) and the surface model state via the bulk formulae by Large and Pond (1981, 1982). Wind forcing is from the composite, mainly satellitederived, blended SeaWinds product at $0.25^{\circ}(\sim 12 \times 28 \mathrm{~km})$ resolution (Zhang et al., 2006). The model hydrographic state is insensitive to highresolution winds, while upper-ocean currents are sensitive to atmospheric scales in the order of $10 \mathrm{~km}$ (Haine et al., 2009). The temperature of the surface layer is relaxed to the Polar Science Center Hydrographic monthly mean Sea Surface Temperature Climatology (PHC3.0, updated from Steele et al. 2001) with a 5-day time scale. No surface relaxation is imposed to the salinity field.

The simulations are run with different timesteps always respecting the Courant-Friedrichs-Lewy condition and their computational times vary. The computation for $C_{n}$ is massive: the timestep is $\Delta t=6 \mathrm{~s}$, the model cycles for $1,324,800$ iterations and the simulation requires a wall-clock time of about three months using 145 processors to achieve 90 days model time. The integration for the corresponding hydrostatic $C_{h}$ simulation is about 3.75 times quicker for a wall-clock time of about 24 days. In the case of the $2-\mathrm{km} P$ simulation, the timestep is $\Delta t=30 \mathrm{~s}$ while the model cycles for 267,840 iterations for a wall-clock time of about one week using 60 processors. 
In terms of processor core days (pcd) used, the $P$ run is almost 31 times quicker than $C_{n}$, covering however a larger area (see Tab. 1). The ocean state is saved every $6 \mathrm{~h}$ in the parent simulation and every $3 \mathrm{~h}$ in both child runs. Results and time averages are shown from the final two months of all the simulations.

Animation 1, included as Supplemental material and available in the online version of this paper at http://dx.doi.org/10.1016/j.dsr.2014.10. 008, shows the results of the one-way nesting approach used in this study. The evolution of the surface salinity for all three simulations shows the turbulent and unstable nature of the front (see also Figs. 1 and 10). The most evident frontal instabilities are the large surface cyclones which break during their propagation and give rise to spirals and hook-like features in surface salinity and surface temperature. The frequency of the cyclones is dictated by the inflow (eastern) boundary where flow characteristics coming from the Denmark Strait are transmitted from the parent to the child grid. At the inflow boundary Animation 1 shows the continuity of the solutions between the two grids, especially when a large cyclone propagates through their interface. More discrepancies can be found at the outflow (western) boundary where the finer solution calculated within the interior child domain is able to radiate away without reflection. Being an outflow boundary, it is also largely unaffected by the coarser parent solution. The rationale here is to mimic the natural difference between inflow and outflow boundaries, like the method of propagation of the flow characteristics (Blayo and Debreu, 2005). 


\section{Results}

\subsection{Along-stream velocities and volume fluxes at the Spill Jet line}

We first consider vertical sections for the along-stream velocity $\left(v_{n}\right)$ normal to the Spill Jet line. Fig. 3a shows $v_{n}$ on July 19, 1800 UTC for the $P$ run. The Spill Jet is the bottom-intensified velocity core banked against the continental slope, where the averaged isopycnals tilt upward toward the shelf break. Downslope, a velocity minimum separates the Spill Jet from the Deep Western Boundary Current (DWBC) core, which lies in 1800-m water depth. Seaward of the Spill Jet, above the DWBC core where the isopycnals tilt upward offshore, the surface-intensified Irminger Current (IC) core is found. The Spill Jet is narrower in both child runs (Figs. 3b and 3c). On average (not shown) it also gets stronger in $C_{h}$ and $C_{n}$ due to a sharper density gradient near the shelfbreak (compare the average isopycnals of Fig. $3 \mathrm{~d}$ with the ones of Figs. 3e and $3 \mathrm{f})$.

We calculate from these sections the volume transports for DSO and Spill Jet waters as in MHP11. The upper density limit for the DSOW is $\sigma_{\theta}=27.8 \mathrm{~kg} \mathrm{~m}^{-3}$, a value commonly chosen to identify the overflow interface (e.g. Dickson and Brown, 1994). Only layers deeper than $450 \mathrm{~m}$ are used for the DSOW calculation to exclude waters with the same density present on the shelf. Fig. 4a shows the time evolution for the DSOW volume transport at the Spill Jet line for the three simulations. DSOW volume transport variability is very similar in the three runs (giving indistinguishable mean values; see Tab. 1). This result is consistent with the idea that DSOW pulses are dictated by the inflow of DSOW cyclones from the parent run. DSOW volume transport values for both child runs are lower than the parent values 
during some periods (e.g. August 12-13 or August 19-20). At these times northward barotropic structures, like that shown in Fig. 6d of Brearley et al. (2012), occupy the Spill Jet line. Their strength and horizontal shear are better resolved in the finer child runs. As in Fig. 6d of Brearley et al. (2012), the northward flows reach the deep part of the section weakening the DWBC cores and reducing the total equatorward transport for the deep layer. The effect is enhanced in the non-hydrostatic case as seen in the bottom right corner of Fig. 3c. Nevertheless, DSOW volume transport averages do not differ significantly (Tab. 1). Most importantly, they compare well with the $-5.2 \mathrm{~Sv}$ observed at slightly different locations upstream and downstream of the Spill Jet line by Dickson and Brown (1994).

For the Spill Jet volume transport, we consider, as in MHP11, waters that: a) are near the continental slope; b) exhibit strong vertical mixing and c) are lighter than DSOW waters. On this basis we select waters that a) lie deeper than $200 \mathrm{~m}$ and less than $50 \mathrm{~km}$ seaward of the shelf break (in the magenta box in Fig. 3); b) are characterized by Richardson numbers $R i<1$ and c) have potential densities $\sigma_{\theta}<27.8 \mathrm{~kg} \mathrm{~m}^{-3}$. Fig. $4 \mathrm{~b}$ shows the time evolution for the Spill Jet volume transports for the three simulations using this definition, which is identical to the one denoted $Q_{2}$ in MHP11. The three curves are very similar. The largest peaks for the child runs compensate periods when Spill Jet values are largest for the coarser $P$ run (for example slack periods in the first 20 days). As a result, Spill Jet average volume transport and variability do not vary significantly in the three runs (see Tab. 1). Average Spill Jet volume transports are in agreement with the -5.0 Sv value observed at the Spill Jet line by Brearley et al. (2012) using a 
comparable definition as used here.

\subsection{Densities, vertical velocities and baroclinic conversion terms at the Spill} Jet line

Vertical sections for average isopycnals are shown in Figs. 3d-f. Far from the shelfbreak the averaged density fields are similar in the three runs. An important difference exists however in the instanteneous density fields of Figs. 3b and 3c. Aside from the expected finer detail achieved in both child runs, the non-hydrostatic isopycnals are more variable in the deep basin. These perturbations affect other fields as shown below.

Now consider the vertical velocity fields at the Spill Jet line. Vertical motion has been shown to change when non-hydrostatic dynamics are included (e.g. Haine and Williams, 2002). Instantaneous vertical velocities in the $P$ run at the Spill Jet line reach a few $\mathrm{cm} \mathrm{s}^{-1}$, due to spilling events and the contemporaneous passage of the DSO-induced cyclones (see Fig. 2). When the two-month average is performed, downward mean vertical motion is observed near the shelfbreak, in the middle of the continental slope and near the DWBC (Fig. 3d). On average, upward motion is observed near the upper continental slope and the offshore edge of the Spill Jet area not in contact with the bottom. Similar average fields hold for both child runs although they show stronger vertical velocities (Figs. 3e and 3f). In the nonhydrostatic case, the perturbations in the deep part of the basin result in time-averaged vertical velocities in the order of a few $\mathrm{mm} \mathrm{s}^{-1}$ for horizontal scales in the $2 \mathrm{~km}<L<10 \mathrm{~km}$ range.

These differences affect the energy conversion. Specifically, they change the baroclinic energy conversion term, defined as $c_{b c}=-g \overline{\rho / w \prime}$, where the 
suffix $b c$ stands for baroclinic. Here $\rho /$ and $w /$ are the deviations of density $\rho$ and vertical velocity $w$ from the two-month averages shown in the lower panels of Fig. 3. This term is an important quantity as positive $c_{b c}$ implies conversion of potential energy to eddy kinetic energy, for example via baroclinic instabilities (Harrison and Robinson, 1978). There are two main positive $c_{b c}$ areas in the simulations (middle panels of Fig. 5). The first area is close to the continental slope, while the second is in mid-water in the deep part of the basin and evident only for the non-hydrostatic case.

We first focus on the positive $c_{b c}$ area close to the slope, which is important for all three runs. To identify which mechanisms are responsible for this $c_{b c}$ positive area, in the next paragraphs, we analyze first the $w /$ and $\rho \prime$ distributions alone, then consider their combined effects.

The $w /$ distributions in this area are shown on the boxplots of Fig. 6a. Boxplots are constructed in order to have approximately \pm 2.7 std and $99.3 \%$ coverage between the two whiskers, where with "std" we indicate the standard deviation of the distribution. Box lines indicate first, second (i.e. the median) and third quartiles, respectively. Outlier values are indicated with black asterisks. In the $P$ run all fluctuations are less than $5 \mathrm{~cm} \mathrm{~s}^{-1}$. In the child runs $99.3 \%$ of $w /$ values are less than $5 \mathrm{~cm} \mathrm{~s}^{-1}$, but outliers approach $10-15 \mathrm{~cm} \mathrm{~s}^{-1}$ in the hydrostatic $C_{h}$ case (downward outliers are strongest). All three distributions for $\rho /$ are shifted toward lighter densities and the median values are slightly negative (Fig. 6b). Both child runs have lighter outlier values than the parent run, however.

A scatter plot in the $\rho /-w /$ plane for points in the positive $c_{b c}$ area near the slope and for the $C_{h}$ run is shown in Fig. 7. The conversion of potential 
energy to eddy kinetic energy in the area is due to the predominance $(27.4 \%)$ of the $\rho \prime<0, w \prime>0$ quadrant, i.e. light waters moving upward. This mainly happens when the trailing edges of DSO cyclones pass the section (see right panels of Fig. 2). The second largest contribution (25.3\%) comes from the $\rho \prime>0, w \prime<0$ quadrant, i.e. dense waters moving downward. This is associated with spilling of dense shelf waters and the leading edges of the DSO cyclones (see left panels of Fig. 2). It is clear from Fig. 7 that extreme downward velocities are associated with a single event, specifically due to the passage of a cyclone and the consequent strong spilling on July 24, at 1200 UTC (see also magenta line in Fig. 4). The situation is substantially similar for the other runs (scatter plots not shown, but percentages for each quadrant are reported in Tab. 1).

The conversion of potential energy to eddy kinetic energy due to the passage of the cyclones dominates in the two hydrostatic runs (Fig. 5). In both, the vertically-integrated baroclinic conversion term $C_{b c}=\int c_{b c} d z$ peaks along the slope, at a distance of about $75 \mathrm{~km}$ at the Spill Jet line (upper panels of Fig. 5). In the non-hydrostatic $C_{n}$ run however, most of the conversion is due to the above cited perturbations and takes place in the deep part of the basin, where the other positive $c_{b c}$ area in the middle of the water column occurs. For the $C_{n}$ run, a $C_{b c}$ peak also occurs at about $75 \mathrm{~km}$ but is weaker. The overall total conversion term $C^{T o t}=\int C_{b c} d s$ values normalized by the $P$ run are listed in Tab. 1 ( $s$ measures distance along the Spill Jet line). When horizontal resolution is increased, the overall baroclinic conversion in the hydrostatic $C_{h}$ run is 1.25 times greater than in the coarser $P$ run. When non-hydrostatic effects are included in the $C_{n}$ run, this overall 
baroclinic conversion ratio of $C_{n}$ to $P$ increases to 1.35 .

Larger differences exist in the kinetic energy due to vertical flow at the Spill Jet line, apparently due to the perturbations in the deep part of the basin. The horizontally-integrated vertical eddy kinetic energy $W^{s}=$ $\int \overline{(w \prime)^{2}} d s$ for the $C_{n}$ run peaks in the middle of the water column and corresponds to the second positive $c_{b c}$ area (see Fig. 5). The maximum is at a depth of $719 \mathrm{~m}$ as shown in the leftmost middle panel of Fig. 5. The lower panels of Fig. 5 show the vertical eddy kinetic energy integrated over the water column, $W^{z}=\int \overline{\left(w^{\prime}\right)^{2}} d z$, as a function of distance along the Spill Jet line. In both hydrostatic $P$ and $C_{h}$ runs, the peak is at about $75 \mathrm{~km}$ and coincides with the positive $c_{b c}$ area close to the slope. After peaking, the energy gradually decreases at larger distances and toward the deep part of the basin. In the non-hydrostatic $C_{n}$ run the vertically-integrated kinetic energy keeps increasing toward the deep part of the basin until reaching the boundaries of the child grid domain. The overall total vertical eddy kinetic enery $E K E^{w}=\iint \overline{(w \prime)^{2}} d z d s$ values normalized by the $P$ run are listed in Tab. 1. The $C_{h}$ and $C_{n}$ runs are about 6 and 34 times more energetic by this measure than the $P$ run. Because the energy keeps increasing toward the boundary however, the value calculated for the $C_{n}$ run does not converge and should be considered as a lower limit.

\subsection{Mid-water sections: evidence of internal gravity waves}

We surmise that the perturbations evident in $C_{n}$ are due to the generation and propagation of internal gravity waves (IGWs; be aware this acronym does not mean inertia-gravity waves) in the deep part of the Irminger Basin. The goal of this section is to provide some initial evidence for this claim, while a 
more detailed analysis and discussion is provided in section 4 .

Our runs capture a peculiar IGW generation mechanism. Near the East Greenland shelf, IGWs are generated by cyclone motion (see Animation 2 included as Supplemental materil and available in the online version of this paper at http://dx.doi.org/10.1016/j.dsr.2014.10.008). The animation shows the time evolution of the vertical velocity $w$ field for the $P$ run in the middle of the water column, at a depth of $719 \mathrm{~m}$, where the horizontallyintegrated vertical eddy kinetic energy for the $C_{n}$ run peaks. Due to the process shown in Fig. 2, strong downward (upward) motions correspond to the leading (trailing) edges of the cyclones. It is clear in the animation that these areas move along the continental slope with the cyclones. After the passage of a cyclone, IGWs are excited and propagate from the slope toward the deeper part of the Basin. Preferential areas for IGW generation are mainly between 50 and $100 \mathrm{~km}$ downstream of the Denmark Strait sill, where Koszalka et al. (2013) identify strong water mass transformation.

This IGW generation occurs in all simulations (not shown). Nevertheless, differences exist between the runs. Fig. 8 shows the instantaneous vertical velocity $w$ fields for the three runs on July 19, at 1800 UTC in the middle of the water column. In all runs, strong downward (upward) motions correspond to the leading (trailing) edge of the strongest and easternmost cyclone, located at this time at about $31^{\circ} \mathrm{W}$ and $65^{\circ} 15^{\prime} \mathrm{N}$. In the $P$ run (Fig. 8a) the cyclone gives rise to an evident hook-like feature (see also Figs. 1 and 10). In both $P$ and $C_{h}$ runs, hydrostatic IGWs have smaller amplitudes than in $C_{n}$ and vertical speeds of $\mathcal{O}(1) \mathrm{cm} \mathrm{s}^{-1}$ can be found only close to the cyclone. The deeper part of the basin is relatively free of IGWs. On the contrary, in 
the $C_{n}$ non-hydrostatic run, the Irminger Basin is filled with large amplitude $\left(1-5 \mathrm{~cm} \mathrm{~s}^{-1}\right)$ IGWs (see also the surface strain and vorticity fields below in Fig. 10). When a 15h-running mean filter is applied to the non-hydrostatic $C_{n}$ run, the filtered $\tilde{w}$ field is smoother and closer to the hydrostatic $C_{h}$ field (Fig. 8d). The filter period is comparable to the local inertial period $T_{f} \sim 13 \mathrm{~h}$ and hence should remove IGWs.

Insights on the spatial scales of these IGWs come from energy spectra. Here, and in the rest of the paper, we use the method of Poje et al. (2010) to calculate kinetic energy spectra: individual spectra are calculated for each zonal section of the domain and then they are averaged in the meridional direction at each time. The kinetic energy spectra at $719 \mathrm{~m}$ depth for the three runs coincide and are almost parallel to $k^{-5 / 3}$ at all scales, for horizontal wavenumber $k$ (not shown). This is because horizontal velocities exceeding $0.65 \mathrm{~m} \mathrm{~s}^{-1}$ exist at depth (see Fig. 3) and dominate the total kinetic energy field. Important differences are found when the vertical kinetic energy field is considered alone at depth. Hydrostatic time-averaged vertical kinetic energy spectra are flat, do not follow either $k^{-5 / 3}$ or $k^{-3}$ slopes, and are weaker than for the non-hydrostatic run (Fig. 9). Most importantly, the $C_{n}$ run shows a broad energy enhancement in the $2 \mathrm{~km}<L<10 \mathrm{~km}$ range where the spectrum approaches $k^{-3}$. After applying the 15h-running mean, most of the enhancement disappears (not shown). The filtered non-hydrostatic vertical kinetic energy still exceeds that of the hydrostatic case in general. Interestingly, the vertical kinetic energy in the hydrostatic $C_{h}$ run is higher at very small scales around the grid spacing due to excessive and unrealistic sinking speeds (see below and Haine and Williams, 2002). 


\subsection{Surface fields}

The model surface circulation is as described in Pickart et al. (2005). Warm and salty Atlantic waters enter from the southern boundary, follow the shelfbreak of the Basin and exit at the south-west corner (see Fig. 1a and Animation 1). They represent the retroflected branch of the Irminger Current which separates from the main stream south of Denmark Strait establishing a cyclonic circulation. Cold and fresh Arctic waters enter the domain from the northern boundary. Some of these waters occupy the inner portion of the Greenland shelf. Some come directly from the upper portion of the Denmark Strait in the East Greenland Current. Once in the domain they flow next to the recirculating branch of the Irminger Current and form the IC/EGC front, situated more or less at the shelfbreak (see Figs. 1a and $10)$.

The IC/EGC front is dominated by the large cyclones which give rise to spirals and hook-like features in surface salinity and temperature (see Figs. 1 and 10). Similar structures had been observed in the satellite thermal imagery of Bruce (1995), see also Fig. 13 in Munk et al. (2000). Eddy diameter varies between 30 and $45 \mathrm{~km}$, as in the observations.

Figs. 10a-c show the surface temperature field on July 19, at 1800 UTC for the three different runs. The snapshots show the same train of five cold cyclones leaving the area south of Denmark Strait along the shelfbreak. The locations and dimensions of the five cyclones do not vary significantly among the runs because cyclone characteristics and timing are dictated at their eastern boundaries by the parent simulation. The simulations instead differ

with respect to details for each cyclone and to the temperature field on the 
shelf. As expected, finer details are achieved in the child runs. The emergence of additional structural complexity at smaller scales indicates submesoscale frontogenesis (Capet et al., 2008a,b,c), permitted by the increase in the grid resolution. Submesoscale variability is stronger at the edges of the mesoscale eddies where large tracer gradients exist.

Figs. 10d-f show the surface vertical vorticity $\xi=\partial v / \partial x-\partial u / \partial y$ fields at the same time. Here $(u, v)$ are the zonal and meridional components of the surface velocity field and $(x, y)$ are the zonal and meridional directions, respectively. In the $P$ run, coherent positive vorticity features correspond to the cyclones while negative vorticity features occur mainly on the inner shelf. In the child runs the cyclones are less coherent in the vorticity field and made up of different vorticity filaments intertwined in strands. The anticyclones on the shelf exhibit an internal structure with positive elongated filaments at their edges. Like in Capet et al. (2008a), the submesoscale vorticity structures are characterized by Rossby numbers $R o>1$ mainly at the edges of the mesoscale eddies ( $R o$ is estimated here by $|\xi| / f$ for Coriolis parameter $f \simeq 1.3 \times 10^{-4} \mathrm{~s}^{-1}$ ). The $C_{h}$ and $C_{n}$ solutions are qualitatively similar except for the deep interior part of the Irminger Basin. In this area small scale vorticity bands appear only in the non-hydrostatic $C_{n}$ run.

Figs. 10g-i show the square of the surface horizontal strain rate $S^{2}=$ $(\partial u / \partial x-\partial v / \partial y)^{2}+(\partial v / \partial x+\partial u / \partial y)^{2}$ on July 19, at 1800 UTC. In all three runs, high strain (deformation) values appear in the frontal area and at the edges of the anticyclones on the shelf. Unlike the parent run, both child runs resolve also the large deformations inside the DSO-induced cyclones. In the deep part of the Basin, large values can be found only in the non-hydrostatic 
run in correspondence with the above cited vorticity bands.

A way to combine horizontal strain rate and vorticity is the Okubo-Weiss parameter (Okubo, 1970; Weiss, 1991) defined as:

$$
Q=S^{2}-\xi^{2}=D^{2}+4\left(\frac{\partial u}{\partial y} \frac{\partial v}{\partial x}-\frac{\partial u}{\partial x} \frac{\partial v}{\partial y}\right)
$$

where $D=\partial u / \partial x+\partial v / \partial y$ is the horizontal divergence of the flow. Surface plots of $Q$ reveal the same structures already identified in Fig. 10 (not shown). The Okubo-Weiss parameter can be used, however, to quantify the differences between the three runs. We calculate the domain-averaged inverse time scale $q^{+}$, introduced by Poje et al. (2010),

$$
q^{+}=\left(\frac{1}{A} \int Q d A\right)^{1 / 2} \text { for } Q>0
$$

where $A$ is the area at the surface of the domain shared by the three runs. By definition, $q^{+}$is a metric of hyperbolicity, and is associated with exponential divergence of particles in both observational (e.g. Haza et al., 2010; Schroeder et al., 2011) and numerical studies (e.g. Poje et al., 2010; Bettencourt et al., 2012). Fig. 11 shows the time evolution for $q^{+}$in the three runs (solid lines). The trends for the three runs are similar with concurrent minima and maxima. Largest (lowest) values are for the $C_{n}(P)$ run. In divergent flows, $S^{2}$ also includes a divergent component which may be predominant (Mensa et al., 2013). The impact of horizontal divergence can be quantified by calculating $q^{+}$without the $D^{2}$ term in Eq. (1). When horizontal divergence is removed, the three curves have basically the same trends but their values are lower (Fig. 11, dotted lines). The small-scale bands due to IGWs and appearing only in the $C_{n}$ run in the deep part of the Basin are still visible in the $Q$ field even when the horizontal divergence is removed 
(not shown). Time-averaged $\overline{q^{+}}$values normalized by the $P$ run are listed in Tab. 1. When horizontal divergence is included, the non-hydrostatic $C_{n}$ run is almost 3 times more hyperbolic than the $P$ run by this measure. The ratio is about 2 for the hydrostatic $C_{h}$ run. When the horizontal divergence is removed, the non-hydrostatic $C_{n}$ run is almost 2.5 times more hyperbolic, while the ratio for $C_{h}$ is 2 .

Time-averaged surface kinetic energy spectra for the three runs are shown in Fig. 12. The three spectra nearly coincide for the smallest wavenumbers (largest scales) until about $L \sim 30-45 \mathrm{~km}$, i.e. the scale of the large eddies seen in Fig. 10. For scales $30-45 \mathrm{~km}<L<100 \mathrm{~km}$, the three curves follow approximately the $k^{-5 / 3}$ slope, consistent with an inverse energy cascade regime. The lower limit of this regime corresponds to scales that are two or three times the upper bound of the Rossby radius estimated from moorings, $R_{d} \sim 15 \mathrm{~km}$ (von Appen et al., 2014b). At scales $L<30 \mathrm{~km}$ the $P$ spectrum steepens approaching $k^{-3}$, consistent with a direct energy cascade to small scales. Due to the better resolved submesoscale frontogenesis, spectra are expected to have shallower slopes at higher wavenumbers as the horizontal resolution increases (Capet et al., 2008a). The transition in both child runs is indeed more gradual and happens over a wider range: Both spectra follow the $k^{-5 / 3}$ slope approximately until about $L \sim 10 \mathrm{~km}$. The direct cascade regime can be observed for $L<10 \mathrm{~km}$, with a slope even steeper than $k^{-3}$ at the very small scales $(L<2 \mathrm{~km})$. The spectra show that the two child runs coincide with the exception of the $2 \mathrm{~km}<L<30 \mathrm{~km}$ range. In this range, the non-hydrostatic spectral density is greater, indicating a more energetic flow than in the hydrostatic counterpart due to IGWs. Indeed, if a 15h- 
running mean filter is applied to the fields before the spectrum calculations, the differences between the two child runs in the $2 \mathrm{~km}<L<30 \mathrm{~km}$ range are reduced and the two spectra almost coincide for all scales (not shown).

\section{Discussion}

This work assesses the effects of horizontal resolution and non-hydrostatic dynamics on the cascading process near East Greenland. As in MHP11, the results show that the cascade is mostly caused by cyclonic eddies which are linked to dense overflow boluses at depth.

Surface fields in the simulations are characterized by frontal distortions of the IC/EGC front. The surface circulation in the three runs does not differ much at larger $(L>30 \mathrm{~km})$ scales, specifically with respect to propagation, location, and size of the surface cyclones. In this scale range, surface kinetic spectra coincide and are consistent with an inverse energy cascade. The increase of horizontal resolution allows the emergence of complex structures at smaller $(L<30 \mathrm{~km})$ scales, likely via submesoscale frontogenesis (e.g. Capet et al., 2008a). As a result, both surface spectra for the child runs are less steep at higher wavenumbers and the transition to the direct energy cascade is more gradual than in the $2-\mathrm{km}$ run.

Surface strain and dispersion diagnostics are sensitive to the increase of horizontal resolution, while non-hydrostatic dynamics increase strain particularly in the deep basin. Large strain and deformation values may lead to high local mixing and affect the averaged inverse time scales $\overline{q^{+}}$, here used to quantify the differences at the surface among the three runs. Global mixing properties are also known to be directly related to Okubo-Weiss-like 
parameters similar to $\overline{q^{+}}$(de Barros et al., 2012). The above results for the normalized $\overline{q^{+}}$values suggest that the mixing potential between Atlantic and Arctic waters at the surface in the non-hydrostatic run is largest and at least 2.5 times greater than in the hydrostatic parent run.

At depth, all three runs show that DSO cyclones convert potential energy to kinetic energy as they slide along the East Greenland continental slope. A first part of the energy conversion is local as it takes place near the slope, due to dense (light) waters moving downwards (upwards) with the leading (trailing) edges of the cyclones. Nevertheless, DSO and Spill Jet time-averaged volume transport values are insensitive to the changes in horizontal resolution and vertical momentum dynamics. By this metric, both lateral stirring and vertical shear instabilities associated with the cascading process are accurately parameterized by the turbulent schemes used at 2-km horizontal resolution. A second energy conversion is non-local and requires non-hydrostatic dynamics. We argue that is because the generation and the propagation of IGWs are more important with non-hydrostatic dynamics (section 3.3).

What are the likely IGW sources and why do the IGWs differ between the runs? We discuss these questions next. IGWs may be generated at the surface (e.g. due to variable surface buoyancy and momentum fluxes) or at the bottom (e.g. due to internal tides and lee waves). Tides are not included in the original HYCOM boundary conditions, so an important IGW source in the real ocean is absent in our simulations. In the Irminger Basin, surface generation occurs most strongly in winter when convection processes and intense "barrier winds" lead to strong buoyancy and momentum forcing 
(Pickart et al., 2003; Moore and Renfrew, 2005). Thus, it is unlikely to be important in our summer 2003 runs. The results clearly indicate that IGWs are associated with the passage of DSO cyclones (Animation 2). We envision different IGW generation mechanisms, all linked to DSO cyclones. First, IGWs could be generated directly when DSO boluses flow down a smooth sloping bottom: wavelike disturbances are observed during the descent of dense currents in the laboratory experiments of Cenedese et al. (2004), while topographic Rossby waves are induced in the wake of dense boluses in the theoretical model of Swaters and Flierl (1991) and Poulin and Swaters (1999). Second, they could be generated by the interaction of the geostrophic flow with bathymetric disturbances at different scales. Griffiths (1983) suggested that near-inertial waves may result from the geostrophic adjustment of unbalanced isopycnal slopes when the flow rounds large scale topographic corners. Nikurashin and Ferrari (2010) showed that they can be generated by geostrophic flows impinging on small scale bathymetric features. Groups of internal waves similar to those in our $C_{n}$ run are indeed seen in the nonhydrostatic simulations over rough topography of Nikurashin et al. (2013). Third, the spilling process initiated by the cyclones (Fig. 2) moves dense shelf waters downslope which then "splash" into the ambient deeper layers and may excite IGWs. This "splashing" process is likely to be the most important and would explain why IGW generation is localized to the area between 50 and $100 \mathrm{~km}$ downstream of the sill, where spilling events are known to be more energetic (Koszalka et al., 2013, see also their supplemental animations). The other candidate mechanisms explain the source localization less well, even though, as pointed out by one reviewer, the localization around 
$30^{\circ} \mathrm{W}$ could also derive from the increased transverse slope and subsequent overflow descent and acceleration as seen by Girton and Sanford (2003).

The linear internal gravity wave dispersion relation in a Boussinesq inviscid fluid under rotation is (Thorpe, 2005)

$$
\omega^{2}=\frac{N^{2}\left(k_{x}^{2}+k_{y}^{2}\right)+k_{z}^{2} f^{2}}{k_{x}^{2}+k_{y}^{2}+k_{z}^{2}}
$$

where $\omega$ is the wave frequency; $k_{x}, k_{y}$ and $k_{z}$ are the horizontal and vertical wavenumbers, respectively; $N$ is the buoyancy frequency; $f=2 \Omega \sin \phi$ is the Coriolis parameter associated with the Earth's angular velocity $\Omega$ at latitude $\phi$. For $\phi=65^{\circ}, f \simeq 1.3 \times 10^{-4} \mathrm{~s}^{-1}$, while $N \simeq 2 \times 10^{-3} \mathrm{~s}^{-1}$ at mid-depth (Pickart et al., 2005, see their Fig. 6). Dispersion relation (3) applies to an infinitely-deep fluid with constant $N$; neither assumption applies to our model. For this reason, (3) is less accurate for small $k_{z}$ away from middepth. Permissible linear IGW frequencies are in the range $f<\omega<N$ and the group velocity of the waves is orthogonal to the direction of the vector wavenumber $\mathbf{K} \equiv\left(k_{x}, k_{y}, k_{z}\right)$. The top panel of Fig. 13 shows $\omega / f$ from (3) as a function of horizontal $k=\sqrt{k_{x}^{2}+k_{y}^{2}}$ and vertical $k_{z}$ wavenumbers. The normalized frequency is always less than $N / f \simeq 15.4$ and asymptotically approaches $N / f$ for small horizontal scales $k^{2} \gg k_{z}^{2}$. Under the hydrostatic approximation, the dispersion relation (3) becomes

$$
\omega^{2}=\frac{N^{2}\left(k_{x}^{2}+k_{y}^{2}\right)+k_{z}^{2} f^{2}}{k_{z}^{2}},
$$

which is a good approximation for equation (3) only for large horizontal scales, when internal waves are long relative to their depth (bottom panel of Fig. 13). For small horizontal scales $k^{2} \gg k_{z}^{2}$, the hydrostatic approximation is quite unphysical because $\omega \rightarrow \infty$ as $k^{2} / k_{z}^{2} \rightarrow \infty$. 
To better resolve high-frequency signals and reinforce the claim about IGWs above, we re-run the three simulations for the first three days of July, saving $w$ at 719 m every 10 minutes. Longer re-run durations at comparable saving frequencies are not feasible. Fig. 14 shows frequency spectra computed from these fields. A prominent peak is evident in the frequency range $f<\omega<N$ in the non-hydrostatic run. The peak is around $\omega=7 f$, which corresponds to a period of 1.9 hours. The origin of this peak is unclear, and is the subject of future study. As pointed out by one reviewer, $\omega=7 f$ is approximately equal to $N / 2$ and subharmonic instabilities may be at work. The emergence of secondary waves with frequency $\omega=N / 2$ is reported in the laboratory experiments of Bourget et al. (2013). It should also be noted that near-inertial energy is likely to be underestimated in Fig. 14 because the re-run duration is comparable to the inertial period. It is clear, however, that activating non-hydrostatic dynamics substantially increases the IGW energy. For frequencies in the $\omega>N$ range, the spectral density in the hydrostatic $C_{h}$ run is higher than in the non-hydrostatic $C_{n}$ run. This finding is consistent with (4): linear IGWs with $\omega>N$ are possible under the hydrostatic approximation. These unphysical waves likely contribute to the excessive and unrealistic sinking speeds at the grid scale (Fig. 6).

Fig. 13 shows that the error incurred for $\omega \approx 7 f$ by making the hydrostatic approximation is small. The linear analysis cannot explain the differences in $w$ shown in Fig. 8 and leading to the different spectra of Fig. 9. We propose that they arise from numerics and are due to the nonlinear evolution of IGWs, which is inherently non-hydrostatic (e.g. Long, 1972). In the vertical momentum equation, the non-hydrostatic pressure 
gradient associated with wave motion opposes the advection terms, which are responsible for non-linear wave steepening. As a result of the balance between non-hydrostatic pressure and advection, a long wavelength IGW may degenerate into a train of high frequency, short wavelength waves, as seen in the laboratory experiments by Horn et al. (2001). It is known that when the non-hydrostatic pressure is neglected, advection can prevail and the waves continue to steepen until their density interfaces are vertical (Daily and Imberger, 2003; Wadzuk and Hodges, 2009). Eventually, these hydrostatic waves tend to overtop themselves causing static instabilities. In our hydrostatic simulations statically unstable fluid is immediately homogenized by the vertical parameterization (Legg and Adcroft, 2003). Thus we argue that, in the $P$ and $C_{h}$ runs, hydrostatic IGWs propagate less far because they steepen excessively and artificially break, leading to the differences observed in section 3.3. An accurate quantification of this artificial mixing is deferred to future studies because it requires the calculation of the increase in the lowest (background) potential energy (e.g. Winters et al., 1995). This is very difficult to achieve in time-consuming realistic simulations with complex geometry and open boundaries like those considered in this study. IGWs do not seem to have a significant impact on the overall mixing of the overflow. This impact needs to be quantified in future studies also in terms of buoyancy flux and drag.

\section{Conclusions}

We consider three different numerical simulations of the Irminger Basin, which differ in horizontal resolution (2 km versus $0.5 \mathrm{~km}$ ) and in approxima- 
tion to the vertical momentum equation. The study is focused on the dense water cascade off the southeast Greenland shelf but may provide some indications for other parts of the world. Specifically, these results are expected to be important in areas where eddies interact with the cascading process and may affect the baroclinic conversion rate. In the Arctic Ocean eddies are observed near the Chukchi Sea shelf (D’Asaro, 1988; Muench et al., 2000) where shelf cascading is well documented (Shapiro et al., 2003). Mesoscale eddies are found along the shelf of the Italian coast (Paschini et al., 1993; CushmanRoisin et al., 2001) where North Adriatic Dense waters are formed (Vilibić and Supić, 2005). Eddies can be also found on the shelf of the Gulf of Lions (Hu et al., 2011), known for dense shelf waters cascading (Durrieu de Madron et al., 2013). Eddies in the Gulf of Aden are known to influence the fate and pathways of the Red Sea overflow water (Ilıcak et al., 2011). Furthermore, the findings about IGWs may be of general interest near continental shelves and ocean ridges where non-linearity and non-hydrostatic effects are known to be important (Apel et al., 1985; Scotti and Pineda, 2006; Klymak et al., 2006; Bourgault et al., 2011; Tessler and Gordon, 2012).

All three high-resolution runs highlight the role played by the cyclonic eddies linked to dense boluses at depth. They cause most of the cascading process, and excite IGWs which provide an efficient mechanism to convert potential energy to kinetic energy in the Irminger Basin. Coarse resolution large-scale models may need specific parameterizations to represent these effects. When the DSO cyclones are resolved, our results indicate that the 2$\mathrm{km}$ resolution hydrostatic run accurately estimates volume transports close to the continental slope, even in the presence of strong variability. It is 
shown here that DSO and Spill Jet time-averaged volume transport values are insensitive to the changes in horizontal resolution and vertical momentum dynamics. This suggests that the turbulent processes near the slope are correctly parameterized in the 2 -km resolution run but not that scales shorter than $2 \mathrm{~km}$ are irrelevant. The $0.5-\mathrm{km}$ resolution runs confirm, at least for summer 2003, that the MHP11 estimate of about 5 Sv for the Spill Jet is robust. This result is especially important in terms of computational costs: indistinguishable time-averaged volume transports are obtained with a run that is more than 31 times less expensive than the non-hydrostatic case. We speculate that a $2-\mathrm{km}$ horizontal resolution may be sufficient for parameterizing near-slope processes and simulating the transport of dense waters cascading off the shelves in other locations.

Non-hydrostatic dynamics are important for IGWs to propagate far from the continental slope, into the deeper part of the Basin. With non-hydrostatic dynamics, additional energy in the $2 \mathrm{~km}<L<30 \mathrm{~km}$ range appears in the surface energy spectra. At depth, when spectra are calculated only for the vertical kinetic energy, the energy enhancement is in the $2 \mathrm{~km}<L<10 \mathrm{~km}$ range. We argue that most of this energy is due to IGWs for the following reasons. First, most of the extra energy in the non-hydrostatic simulation is removed by a running mean filter which removes time scales shorter than the inertial period. Second, for a 3-day period, the extra energy peaks at $\omega \approx 7 f$. Third, hydrostatic IGWs likely steepen, overturn and are dissipated. Finally, similar deep energy enhancements in non-hydrostatic simulations have been attributed to IGWs generated at the bottom (Nikurashin et al., 2013).

Our findings suggest that high $(<1 \mathrm{~km})$ horizontal resolutions are needed 
to resolve the emergence of additional structural submesoscale complexity at smaller scales. Larger surface strain values are found when the horizontal resolution is increased, while non-hydrostatic dynamics increase strain particularly in the deep basin. As a result, the $0.5-\mathrm{km}$ resolution hydrostatic and non-hydrostatic runs are 2.0 and 2.5 times more hyperbolic than the $2-\mathrm{km}$ resolution hydrostatic run, respectively. Close to the shelf at the Spill Jet line, vertical velocities do not exceed $\pm 5 \mathrm{~cm} \mathrm{~s}^{-1}$ in the 2 - $\mathrm{km}$ resolution run. In the hydrostatic $0.5-\mathrm{km}$ resolution run vertical speeds occasionally reach almost $15 \mathrm{~cm} \mathrm{~s}^{-1}$. The non-hydrostatic $0.5-\mathrm{km}$ resolution vertical speeds are intermediate. Excessive sinking speeds of $15 \mathrm{~cm} \mathrm{~s}^{-1}$ have been also found in high-resolution hydrostatic convective simulations (Haine and Williams, 2002). In both cases, similar unrealistic plume processes likely cause overturning at the model grid scale.

The baroclinic energy conversion differs between the three runs. It increases with resolution and the ratio for the two hydrostatic runs is 1.25 . In the non-hydrostatic run, the conversion is mainly due to IGWs and takes place in the deep part of the basin. As a result, it is 1.35 times greater than the 2-km resolution hydrostatic run. The IGW impact on the energetics is strong. Compared with the 2-km resolution hydrostatic run, a 34-fold increase in vertical kinetic energy is observed in the non-hydrostatic run, mainly due to IGWs that radiate from the shelf toward the deeper part of the basin. These results show the sensitivity of energy diagnostics to horizontal resolution and vertical momentum dynamics, particularly in areas dominated by geostrophic vortices impinging on bathymetric features. In these cases, IGWs can radiate directly from geostrophic flows (Nikurashin 
and Ferrari, 2010) and transfer energy to small dissipation scales through non-linear interactions and wave breaking. This route for energy dissipation dominates in some cases (e.g. Nikurashin et al., 2013), but our results show that it may be strongly underestimated in hydrostatic simulations. Therefore, computationally expensive simulations with non-hydrostatic dynamics and grid spacing less than $1 \mathrm{~km}$ are justified for other parts of the world when the focus is on the offshore effects of the cascading process.

\section{Acknowledgments}

The comments and discussions with Inga Koszalka are greatly acknowledged. This work was supported by the U.S. National Science Foundation, Grants OCI-108849, OCE-0726640 and OCI-0904338 and by the Italian Ministry of University and Research through the RITMARE Flagship Project. All simulations and data-intensive computations have been performed on the Homewood High-Performance Cluster at the Institute of Data Intensive Engineering and Science of the Johns Hopkins University. 


\section{List of Figures}

1 Plan view of the numerical domains showing the sea surface salinity field on 19 July, 1800 UTC. The 20, 40, 60, 80, 100, $200,300,400,500,600,700,800,1000,1500,2000$, and 2500$\mathrm{m}$ isobaths are in gray. The Spill Jet line is in magenta. a) Large domain for the $2-\mathrm{km}$, hydrostatic parent $(P)$ run. The black box denotes the boundaries for the closeup in b) and the child grid. b) Closeup around the Spill Jet line for the $P$ run.

c) Domain for the $0.5-\mathrm{km}$ hydrostatic child $\left(C_{h}\right)$ run. d) As in c) but for the $0.5-\mathrm{km}$ non-hydrostatic child $\left(C_{n}\right)$ run . . . . 56 
2 The eddy-induced cascading process according to Magaldi et al. (2011). Upper panels: Sequence of sea-surface temperature $\left({ }^{\circ} \mathrm{C}\right.$ ) images in the parent $P$ simulation (a frame every 12 hours). The yellow arrow shows a cyclone moving along the edge of the continental shelf. As its leading edge approaches the Spill Jet line, it draws dense shelf water offshore and initiates the spilling. Middle panels: Corresponding model crossstream lateral circulation at the Spill Jet section. Downward (upward) intense motion is associated with the leading (trailing) edge of the cyclone. Lower panels: Schematic view of the process: The continental shelf is the shallow part at the top of each frame. The magenta plane is the Spill Jet section. The cyan and violet surfaces are sheets of constant density (violet is denser and deeper). For details refer to Magaldi et al. (2011) noting that panels (b)-(c) and (e)-(f) are new and allow a visual comparison between different phases of the process. . 57

3 Upper panels: along-stream velocities $v_{n}\left(\mathrm{~m} \mathrm{~s}^{-1}\right.$, color $)$ normal to the Spill Jet line and potential density contours $\sigma_{\theta}(\mathrm{kg}$ $\mathrm{m}^{-3}$, black lines) on 19 July, 1800 UTC. Positive $v_{n}$ values stand for equatorward flow. Lower panels: time-averaged vertical velocities $\bar{w}\left(\mathrm{~m} \mathrm{~s}^{-1}\right.$, color $)$ and time-averaged potential density contours $\overline{\sigma_{\theta}}\left(\mathrm{kg} \mathrm{m}^{-3}\right.$, black lines) at the Spill Jet line. Positive (negative) values are for upward (downward) vertical velocities. The magenta box is the region used to calculate volume transports for the Spill Jet (see text) . . . . . . . . 58 
4 Time evolution for the volume transport (in Sv) of (a) Denmark Strait Overflow and (b) Spill Jet waters at the Spill Jet line in the three runs. Negative values stand for equatorward transports. The magenta vertical lines indicate the times July 19, 1800 UTC and July 24, 1200 UTC used in other figures. Transport values are calculated according to the $Q_{2}$ definition

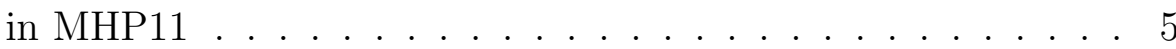

5 Baroclinic conversion terms and vertical eddy kinetic energy for the three runs at the Spill Jet line. Upper panels: verticallyintegrated baroclinic conversion term $C_{b c}=\int c_{b c} d z$ as a function of distance, $s$, at the Spill Jet line. Middle panels: baroclinic conversion term $c_{b c}$ (color) and time-averaged potential density contours $\overline{\sigma_{\theta}}$ (black lines) at the Spill Jet line. Lower panels: vertically-integrated vertical eddy kinetic energy $W^{z}=\int \overline{\left(w^{\prime}\right)^{2}} d z$ as a function of distance at the Spill Jet line. Insets show the same curves with different $y$-axis limits. Leftmost middle panel: horizontally-integrated vertical eddy kinetic energy $W^{s}=\int \overline{\left(w^{\prime}\right)^{2}} d s$ as a function of depth. Black, red and blue colors stand for the $P, C_{h}$ and $C_{n}$ runs, respectively 60 
6 Boxplots for $w^{\prime}$ (top panel) and $\rho^{\prime}$ (bottom panel) distributions in the positive $c_{b c}$ area close to the slope for the three runs (see Fig. 5). Boxplots are constructed in order to have approximately \pm 2.7 std and $99.3 \%$ coverage between the two whiskers, where with "std" we indicate the standard deviation of the distribution. Box lines indicate first, second and third quartiles, respectively. Outlier values are indicated with black asterisks ....................... . . . 61

$7 \quad$ Scatter and box plots for the $\rho$ and $w /$ distributions for $c_{b c}>0$ points near the slope in the $C_{h}$ run (see Figs. 5 and 6 ). The top right panel shows which points in the section are selected, $N_{p}$ indicates their number. $\mathcal{A}=-\rho / w /$ indicates the sign of the contributions to $c_{b c}$ in each quadrant . . . . . . . . 62

8 (a)-(c) Vertical velocity fields in the three runs at $719 \mathrm{~m}$ depth on 19 July, 1800 UTC. (d) As (c) but after applying a 15hrunning mean. The colorbar in the figure is different from the one used in Animation 2 for the $P$ run. The black line in (a) indicates the same $8{ }^{\circ} \mathrm{C}$ sea surface temperature contour as in Fig. 10a ....................... 63

9 Time-averaged vertical kinetic energy spectra at $719 \mathrm{~m}$ depth. Dashed lines indicate the $k^{-5 / 3}$ and $k^{-3}$ slopes . . . . . . . . . 64 
10 (a)-(c) Sea surface temperature, (d)-(f) vorticity and (g)-(i) strain fields on 19 July, 1800 UTC. The yellow line in (a) indicates the $8{ }^{\circ} \mathrm{C}$ sea surface temperature contour. The yellow arrows in (a)-(c) show five cyclones moving along the shelfbreak. The black lines in the colorbars of (d)-(f) indicate the $\pm \xi / f=1$ values. The $500 \mathrm{~m}$ isobath is in magenta in (d)-(i) for reference . . . . . . . . . . . . . . . 65

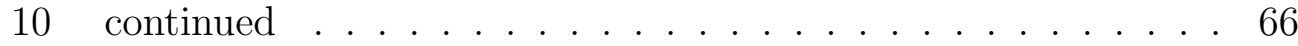

11 Time evolution for $q^{+}\left(\mathrm{s}^{-1}\right.$; see Eq. (2)) in the three runs. The solid (dotted) lines indicate calculations with (without) horizontal divergence. The magenta vertical line indicates the time July 19, 1800 UTC . . . . . . . . . . . . . . . . . . . 67

12 Surface kinetic energy spectra $E(k)$ averaged in time. Dashed lines indicate the $k^{-5 / 3}$ and $k^{-3}$ slopes . . . . . . . . . . 68 
13 Comparison between non-hydrostatic (top) and hydrostatic (bottom) linear IGW dispersion relations, Eqs. (3) and (4). Colors show $\omega / f$ as a function of horizontal and vertical wavenumbers $k$ and $k_{z}$. The white dashed lines indicate the approximate maximum depth $H$ in the area common to all simulations and the maximum and minimum resolutions $(\Delta x, \Delta z)$ used in the three runs. For clarity values are indicated only in the top panel. The black lines in the colorbars and bottom panel indicate the $N / f$ value. The magenta box indicates the $2 \mathrm{~km}$ $<L<10 \mathrm{~km}$ and $5 f<\omega<9 f$ ranges from Figs. 9 and 14 where extra energy is found in the non-hydrostatic run. The linear dispersion relations assume infinite-depth constant $N$ ocean: they are most accurate for large $k_{z} \ldots \ldots$. . . . . . 69

14 Spatially-averaged spectral density of vertical speed in the three runs at $719 \mathrm{~m}$ depth during 1 July, 0000 UTC to 4 July, 0000 UTC. The magenta dashed lines indicate (from left to right) the inertial $f \simeq 1.3 \times 10^{-4} \mathrm{~s}^{-1}$, the $\omega=7 f$ and buoyancy $N \simeq 2 \times 10^{-3} \mathrm{~s}^{-1}$ frequencies, respectively . . . . . 70 
1 Animation 1: Evolution of the sea surface salinity in the three simulations. Top panels show the hydrostatic parent $(P)$ run, entire domain (left) and closeup (right). Bottom panels show the hydrostatic $\left(C_{h}\right.$, left) and non-hydrostatic $\left(C_{n}\right.$, right) child runs. The black box denotes the boundaries for the child grid, the Spill Jet line is in magenta and isobaths are in gray as in Fig. 1. A frame every 3 hours is shown for the child runs. A frame every 6 hours is shown for the parent run. Duration: from July 1 to September 1, 2003 . . . . . . . . . . . . . 71

2 Animation 2: Evolution of the vertical velocity field in the parent $P$ run at $719 \mathrm{~m}$ depth showing evidence for IGWs. The black box denotes the boundaries for the child grid while the Spill Jet line is in magenta. A frame every 6 hours is shown. Duration: from July 1 to September 1, 2003 . . . . . . 72 


\begin{tabular}{||c||c|c|c||}
\hline \hline Metric & $P$, Hydr. $2 \mathrm{~km}$ & $C_{h}$, Hydr. 500m & $C_{n}$, Non-Hydr. 500m \\
\hline \hline Cores ratio $\left(\mathrm{pcd} / \mathrm{pcd}_{P}\right)$ & 1 & 8.3 & 31.1 \\
\hline DSOW flux $(\mathrm{avg} \pm \mathrm{std})$ & $-6.1 \pm 2.8 \mathrm{~Sv}$ & $-6.0 \pm 2.8 \mathrm{~Sv}$ & $-5.5 \pm 2.7 \mathrm{~Sv}$ \\
\hline SJW flux $($ avg $\pm \mathrm{std})$ & $-4.9 \pm 1.7 \mathrm{~Sv}$ & $-4.8 \pm 1.7 \mathrm{~Sv}$ & $-4.8 \pm 1.7 \mathrm{~Sv}$ \\
\hline $\mathcal{A}<0, \rho^{\prime} \geq 0, w \prime \geq 0$ & $22.1 \%$ & $23.2 \%$ & $23.1 \%$ \\
\hline $\mathcal{A}>0, \rho^{\prime} \geq 0, w \prime<0$, leading edge & $25.8 \%$ & $25.3 \%$ & $25.2 \%$ \\
\hline $\mathcal{A}>0, \rho \prime<0, w \prime \geq 0$, trailing edge & $28.5 \%$ & $27.4 \%$ & $27.3 \%$ \\
\hline $\mathcal{A}<0, \rho \prime<0, w \prime<0$ & $23.6 \%$ & $24.1 \%$ & $24.4 \%$ \\
\hline$C^{T o t} / C_{P}^{T o t}$ & 1 & 1.25 & 1.35 \\
\hline$E K E^{w} / E K E_{P}^{w}$ & 1 & 5.65 & {$[33.94]$} \\
\hline$\overline{q^{+}} / \overline{q_{P}^{+}}$ & $1(1)$ & $2.17(2.00)$ & $2.92(2.51)$ \\
\hline \hline
\end{tabular}

Table 1: Quantitative metrics for the three runs. Calculations of $\overline{q^{+}}$performed without the horizontal divergence term are in parentheses. $\mathcal{A}=-\rho / w /$ indicates the sign of the contributions to $c_{b c}$ in each quadrant as in Fig. 7. $C^{T o t}$ and $E K E^{w}$ denote the integrals $C^{T o t}=\iint c_{b c} d z d s$ and $E K E^{w}=\iint \overline{(w \prime)^{2}} d z d s$, respectively. The ratio $E K E^{w} / E K E_{P}^{w}$ for the $C_{n}$ case is in square brackets to indicate that the integral does not converge.

\section{References}

Adcroft, A., Hill, C., Marshall, J., 1997. Representation of topography by shaved cells in a height coordinate ocean model. J. Mar. Syst. 125 (9), 2293-2315, doi:10.1175/1520-0493(1997)125<2293:ROTBSC >2.0.CO;2.

Apel, J. R., Holbrook, J. R., Liu, A. K., Tsai, J. J., 1985. The Sulu Sea internal soliton experiment. J. Phys. Oceanogr. 15 (12), 1625-1651, doi:10.1175/1520-0485(1985)015<1625:TSSISE >2.0.CO;2. 
Bettencourt, J. H., López, C., Hernández-García, E., 2012. Oceanic threedimensional Lagrangian coherent structures: a study of a mesoscale eddy in the Benguela upwelling region. Ocean Modell. 51, 73-83, doi:10.1016/j.ocemod.2012.04.004.

Blayo, E., Debreu, L., 2005. Revisiting open boundary conditions from the point of view of characteristic variables. Ocean Modell. 9, 231-252.

Bleck, R., 2002. An oceanic general circulation model framed in hybrid isopycnic-Cartesian coordinates. Ocean Modell. 4 (1), 55-82, doi:10.1016/S1463-5003(01)00012-9.

Bourgault, D., Jaines, D. C., Galbraith, P. S., 2011. Observations of a largeamplitude internal wave train and its reflection off a steep slope. J. Phys. Oceanogr. 41 (3), 586-600, doi:10.1175/2010JPO4464.1.

Bourget, B., Dauxois, T., Joubaud, S., Odier, P., 2013. Experimental study of parametric subharmonic instability for internal plane waves. J. Fluid Mech. 723 (5), 1-20, doi:10.1017/jfm.2013.78.

Brearley, J. A., Pickart, R. S., Valdimarsson, H., Jónsson, S., Schmitt, R. W., Haine, T. W. N., 2012. The East Greenland boundary current system south of Denmark Strait. Deep Sea Res. I 65 (0), 1-19, doi:10.1016/j.dsr.2012.01.001.

Bruce, J. G., 1995. Eddies southwest of the Denmark Strait. Deep Sea Res. I 42 (1), 13-17, doi:10.1016/0967-0637(94)00040-Y.

Budillon, G., Castagno, P., Aliani, S., Spezie, G., Padman, L., 2011. Thermohaline variability and Antarctic bottom water formation at 
the Ross Sea shelf break. Deep Sea Res. I 58 (10), 1002-1018, doi:10.1016j.dsr.2011.07.002.

Campin, J.-M., Adcroft, A., Hill, C., Marshall, J., 2004. Conservation of properties in a free-surface model. Ocean Modell. 6 (3), 221-284, doi:10.1016/S1463-5003(03)00009-X.

Canals, M., Puig, P., Durrieu de Madron, X., Heussner, S., Palanques, A., Fabres, J., 2006. Flushing submarine canyons. Nature 444 (7117), 354-357, doi:10.1038/nature05271.

Capet, X., McWilliams, J. C., Molemaker, M. J., Shchepetkin, A. F., 2008a. Mesoscale to submesoscale transition in the California Current System. Part I: flow structure, eddy flux, and observational tests. J. Phys. Oceanogr. 38 (1), 29-43, doi:10.1175/2007JPO3671.1.

Capet, X., McWilliams, J. C., Molemaker, M. J., Shchepetkin, A. F., 2008b. Mesoscale to submesoscale transition in the California Current System. Part II: frontal processes. J. Phys. Oceanogr. 38 (1), 44-64, doi:10.1175/2007JPO3672.1.

Capet, X., McWilliams, J. C., Molemaker, M. J., Shchepetkin, A. F., 2008c. Mesoscale to submesoscale transition in the California Current System. Part III: energy balance and flux. J. Phys. Oceanogr. 38 (10), 2256-2269, doi:10.1175/2008JPO3810.1.

Cenedese, C., Whitehead, J. A., Ascarelli, T. A., Ohiwa, M., 2004. A dense current flowing down a sloping bottom in a ro- 
tating fluid. J. Phys. Oceanogr. 34 (1), 188-203, doi:10.1175/15200485(2004)034<0188:ADCFDA > 2.0.CO;2.

Chapman, D. C., 1985. Numerical treatment of cross-shelf open boundaries in a barotropic coastal ocean model. J. Phys. Oceanogr. 15 (3), 1060-1075, doi:10.1175/1520-0485(1985)015<1060:NTOCSO >2.0.CO;2.

Chassignet, E. P., Hurlburt, H. E., Metzger, E. J., Smedstad, O. M., Cummings, J. A., Halliwell, G. R., Bleck, R., Baraille, R., Wallcraft, A. J., Lozano, C., Tolman, H. L., Srinivasan, A., Hankin, S., Cornillon, P., Weisberg, R., Barth, A., He, R., Werner, F., Wilkin, J., 2009. US GODAE Global Ocean Prediction with the HYbrid Coordinate Ocean Model (HYCOM). Oceanography 22 (2, (Sp. Iss.)), 64-75.

Chassignet, E. P., Hurlburt, H. E., Smedstad, O. M., Halliwell, G. R., Hogan, P. J., Wallcraft, A. J., Baraille, R., Bleck, R., 2007. The HYCOM (HYbrid Coordinate Ocean Model) data assimilative system. J. Mar. Res. 65 (1-4), 60-83, doi:10.1016/j.jmarsys.2005.09.016.

Chassignet, E. P., Smith, L. T., Halliwell, G. R., Bleck, R., 2003. North Atlantic simulations with the HYbrid Coordinate Ocean Model (HY$\mathrm{COM}$ ): impact of the vertical coordinate choice, reference pressure, and thermobaricity. J. Phys. Oceanogr. 33 (12), 2504-2526, doi:10.1175/15200485(2003)033<2504:NASWTH >2.0.CO;2.

Cushman-Roisin, B., Gačić, M., Poulain, P.-M., Artegiani, A., 2001. Physical Oceanography of the Adriatic Sea: Past, Present and Future. Kluwer Academic Publishers, 320 pp. 
Daily, C., Imberger, J., 2003. Modelling solitons under the hydrostatic and Boussinesq approximations. Int. J. Numer. Meth. Fluids 43 (3), 231-252, doi:10.1002/fld.600.

D'Asaro, E. A., 1988. Observations of small eddies in the Beaufort Sea. J. Geophys. Res. 93 (C6), 6669-6684, doi:10.1029/JC093iC06p06669.

de Barros, F. P. J., Dentz, M., Koch, J., , Nowak, W., 2012. Flow topology and scalar mixing in spatially heterogeneous flow fields. Geophys. Res. Lett. 39 (8), L08404, doi:10.1029/2012GL051302.

Dickson, R. R., Brown, J., 1994. The production of North Atlantic Deep Water: sources, rates, and pathways. J. Geophys. Res. 99 (C6), 12319 12341, doi:10.1029/94JC00530.

Dickson, R. R., Dye, S., Jónsson, S., Köhl, A., Macrander, A., Marnela, M., Meincke, J., Olsen, S. M., Rudels, B., Valdimarsson, H., Voet, G., 2008. The overflow flux west of Iceland: variability, origins and forcing. In: Dickson, M., Rhines, E. (Eds.), Arctic-Subarctic Ocean Fluxes: defining the role of the Northern Seas in climate. Springer-Verlag, pp. 443-474.

Durrieu de Madron, X., Houpert, L., Puig, P., Sanchez-Vidal, A., Testor, P., Bosse, A., Estournel, C., Somot, S., Bourrin, F., Bouin, M. N., Beauverger, M., Beguery, L., Calafat, A., Canals, M., Cassou, C., Coppola, L., Dausse, D., D’Ortenzio, F., Font, J., Heussner, S., Kunesch, S., Lefevre, D., Goff, H. L., Martín, J., Mortier, L., Palanques, A., Raimbault, P., 2013. Interaction of dense shelf water cascading and open-sea convection 
in the northwestern Mediterranean during Winter 2012. Geophys. Res. Lett. 40 (7), 1379-1385, doi:10.1002/grl.50331.

Falina, A., Sarafanov, A., Mercier, H., Lherminier, P., Sokov, A., Daniault, N., 2012. On the cascading of dense shelf waters in the Irminger Sea. J. Phys. Oceanogr. 42 (12), 2254-2267, doi:10.1175/JPO-D-12-012.1.

Girton, J. B., Sanford, T. B., 2003. Descent and modification of the overflow plume in the Denmark Strait. J. Phys. Oceanogr. 33 (7), 1351-1364, doi:10.1175/1520-0485(2003)033<1351:DAMOTO>2.0.CO;2.

Girton, J. B., Sanford, T. B., Käse, R. H., 2001. Synoptic sections of the Denmark Strait Overflow. Geophys. Res. Lett. 28 (8), 1619-1622, doi:10.1029/2000GL011970.

Gordon, A. L., Orsi, A. H., Muench, R., Huber, B. A., Zambianchi, E., Visbeck, M., 2009. Western Ross Sea continental slope gravity currents. Deep Sea Res. II 56 (13-14), 796-817, doi:10.1016/j.dsr2.2008.10.037.

Griffiths, R. W., 1983. Internal wave drag and the production of intense vortices by turbulent gravity currents, with implications for the sinking of bottom waters. Ocean Modell. 50, 9-12.

Haine, T. W. N., 2010. High-frequency fluctuations in Denmark Strait transport. Geophys. Res. Lett. 37 (14), L14601, doi:10.1029/2010GL043272.

Haine, T. W. N., Williams, P. D., 2002. The role of nonhydrostatic dynamics in controlling development of a surface ocean front. Ocean Modell. 4 (2), 121-135, doi:10.1016/S1463-5003(01)00014-2. 
Haine, T. W. N., Zhang, S., Moore, G. W. K., Renfrew, I. A., 2009. On the impact of high-resolution, high-frequency meteorological forcing on Denmark Strait ocean circulation. Q. J. R. Meteorol. Soc. 135 (645), 20672085, doi:10.1002/qj.505.

Halliwell, G. R., 2004. Evaluation of vertical coordinate and vertical mixing algorithms in the HYbrid-Coordinate Ocean Model (HYCOM). Ocean Modell. 7 (3-4), 285-322, doi:10.1016/j.ocemod.2003.10.002.

Harden, B. E., Pickart, R. S., Renfrew, I. A., 2014. Offshore transport of dense water from the East Greenland shelf. J. Phys. Oceanogr. 44, 229245, doi:10.1175/JPO-D-12-0218.1.

Harrison, D. E., Robinson, A. R., 1978. Energy analysis of open regions of turbulent flows: mean eddy energetics of a numerical ocean circulation experiment. Dyn. Atmos. Oceans 2, 185-211.

Haza, A. C., Özgökmen, T. M., Griffa, A., Molcard, A., Poulain, P.-M., Peggion, G., 2010. Transport properties in small-scale coastal flows: relative dispersion from VHF radar measurements in the Gulf of La Spezia. Ocean Dyn. 60 (4), 861-882, doi:10.1007/s10236-010-0301-7.

Horn, D. A., Imberger, J., Ivey, G. N., 2001. The degeneration of largescale interfacial gravity waves in lakes. J. Fluid Mech. 434 (5), 181-207, doi:10.1017/S0022112001003536.

Hu, Z. Y., Petrenko, A. A., Doglioli, A. M., Dekeyser, I., 2011. Study of a mesoscale anticyclonic eddy in the western part of the gulf of lion. J. Mar. Sys. 88 (1), 3-11, doi:10.1016/j.jmarsys.2011.02.008. 
Ilıcak, M., Özgökmen, T. M., Johns, W. E., 2011. How does the Red Sea outflow water interact with Gulf of Aden eddies? Ocean Modell. 36 (1-2), 133-148, doi:10.1016/j.ocemod.2010.10.006.

Ivanov, V. V., Shapiro, G. I., Huthnance, J. M., Aleynik, D. L., Golovin, P., 2004. Cascades of dense water around the world ocean. Prog. Oceanogr. 60 (1), 47-98, doi:10.1016/j.pocean.2003.12.002.

Jackett, D. R., McDougall, T. J., 1995. Minimal adjustment of hydrostatic profiles to achieve static stability. J. Atmos. Ocean. Technol. 12 (2), 381389, doi:10.1175/1520-0426(1995)012<0381:MAOHPT >2.0.CO;2.

Jakobsson, M., Macnab, R., Mayer, L., Anderson, R., Edwards, M., Hatzky, J., Schenke, H.-W., Johnson, P., 2008. An improved bathymetric portrayal of the Arctic Ocean: implications for ocean modeling and geological, geophysical and oceanographic analyses. Geophys. Res. Lett. 35 (7), L07602, doi:10.1029/2008GL033520.

Jochumsen, K., Quadfasel, D., Valdimarsson, H., Jónsson, S., 2012. Variability of the Denmark Strait overflow: moored time series from 1996-2011. J. Geophys. Res. 117, C12003, doi:10.1029/2012JC008244.

Jones, E. P., Rudels, B., Anderson, L. G., 1995. Deep waters of the Arctic Ocean: origins and circulation. Deep Sea Res. I 42 (5), 737-760, doi:10.1016/0967-0637(95)00013-V.

Kalnay, E., Kanamitsu, M., Kistler, R., Collins, W., Deaven, D., Gandin, L., Iredell, M., Saha, S., White, G., Woollen, J., Zhu, 
Y., Leetmaa, A., Reynolds, R., Chelliah, M., Ebisuzaki, W., Higgins, W., Janowiak, J., Mo, K. C., Ropelewski, C., Wang, J., Jenne, R., Dennis, J., 1996. The NCEP/NCAR 40-Year Reanalysis Project. Bull. Am. Meteorol. Soc. 77 (3), 437-471, doi:10.1175/15200477(1996)077<0437:TNYRP $>2.0$. CO;2.

Käse, R. H., Girton, J. B., Sanford, T. B., 2003. Structure and variability of the Denmark Strait overflow: model and observations. J. Geophys. Res. 108, C63181, doi:10.1029/2002JC001548.

Kim, K., Chang, K.-I., Kang, D.-J., Kim, Y.-H., Lee, J.-H., 2008. Review of recent findings on the water masses and circulation in the East Sea (Sea of Japan). J. Oceanogr. 64 (5), 721-735, doi:10.1007/s10872-008-0061-x.

Klymak, J. M., Pinkel, R., Liu, C.-T., Liu, A. K., David, L., 2006. Prototypical solitons in the South China Sea. Geophys. Res. Lett. 33, L11607, doi:10.1029/2006GL025932.

Koszalka, I., Haine, T. W. N., Magaldi, M. G., 2013. Fates and travel times of Denmark Strait Overflow Water in the Irminger Basin. J. Phys. Oceanogr. 43 (12), 2611-2628, doi:10.1175/JPO-D-13-023.1.

Large, W. G., McWilliams, J. C., Doney, S. C., 1994. Oceanic vertical mixing: a review and a model with a nonlocal boundary layer parameterization. Rev. Geophys. 32 (4), 363-403, doi:10.1029/94RG01872.

Large, W. G., Pond, S., 1981. Open ocean momentum flux measurements in moderate to strong winds. J. Phys. Oceanogr. 11 (2), 324-336, doi:10.1175/1520-0485(1981)011<0324:OOMFMI>2.0.CO;2. 
Large, W. G., Pond, S., 1982. Sensible and latent heat flux measurements over the ocean. J. Phys. Oceanogr. 12 (5), 464-482, doi:10.1175/15200485(1982)012<0464:SALHFM >2.0.CO;2.

Legg, S., Adcroft, A., 2003. Internal wave breaking at concave and convex continental slopes. J. Phys. Oceanogr. 33 (11), 2224-2246, doi:10.1175/1520-0485(2003)033<2224:IWBACA >2.0.CO;2.

Legg, S., Hallberg, R. W., Girton, J. B., 2006. Comparison of entrainment in overflows simulated by z-coordinate, isopycnal and non-hydrostatic models. Ocean Modelling 11 (1-2), 69-97, doi:10.1016/j.ocemod.2004.11.006.

Leith, C. E., 1967. Diffusion approximation for two-dimensional turbulence. Phys. Fluids 10 (7), 1409-1416, doi:10.1063/1.1762300.

Leith, C. E., 1996. Stochastic models of chaotic systems. Physica D 98 (2-4), 481-491, doi:10.1016/0167-2789(96)00107-8.

Long, R. R., 1972. The steepening of long, internal waves. Tellus 24 (2), 88-99, doi:10.1111/j.2153-3490.1972.tb01536.x.

Macrander, A., Käse, R. H., Send, U., Valdemarsson, H., Jónsson, S., 2007. Spatial and temporal structure of the Denmark Strait Overflow revealed by acoustic observations. Ocean Dyn. 57 (2), 75-89, doi:10.1007/s10236007-0101-x.

Magaldi, M. G., Haine, T. W. N., Pickart, R. S., 2011. On the nature and variability of the East Greenland Spill Jet: a case study in summer 2003. J. Phys. Oceanogr. 41 (12), 2307-2327. 
Marshall, J., Adcroft, A., Hill, C., Perelman, L., Heisey, C., 1997. A finite-volume, incompressible Navier Stokes model for studies of the ocean on parallel computers. J. Geophys. Res. 102 (C3), 5753-5766, doi:10.1029/96JC02775.

Mensa, J. A., Garraffo, Z., Griffa, A., Özgökmen, T. M., Haza, A., Veneziani, M., 2013. Seasonality of the submesoscale dynamics in the Gulf Stream region. Ocean Dyn. 63 (8), 923-941, doi:10.1007/s10236-013-0633-1.

Mihanović, H., Vilibić, I., Carniel, S., Tudor, M., Russo, A., Bergamasco, A., Bubić, N., Ljubešić, Z., Viličić, D., Boldrin, A., Malačič, V., Celio, M., Comici, C., Raicich, F., 2013. Exceptional dense water formation on the Adriatic shelf in the winter of 2012. Ocean Sci. 9 (3), 561-572, doi:10.5194/os-9-561-2013.

Moore, G. W. K., Renfrew, I. A., 2005. Tip jets and barrier winds: a QuikSCAT climatology of high wind speed events around Greenland. J. Climate 18 (18), 3713-3725, doi:10.1175/JCLI3455.1.

Muench, R. D., Gunn, J. T., Whitledge, T. E., Schlosser, P., Smethie, W., 2000. An Arctic Ocean cold core eddy. J. Geophys. Res. 105 (C10), 2399724006, doi:10.1029/2000JC000212.

Munk, W., Armi, L., Fischer, K., Zachariasen, F., 2000. Spirals on the sea. Proc. R. Soc. Lond. A 456 (1997), 1217-1280, doi:10.1098/rspa.2000.0560.

Nikurashin, M., Ferrari, R., 2010. Radiation and dissipation of internal waves generated by geostrophic motions impinging on small- 
scale topography: Theory. J. Phys. Oceanogr. 40 (5), 1055-1074, doi:10.1175/2009JPO4199.1.

Nikurashin, M., Vallis, G. K., Adcroft, A., 2013. Routes to energy dissipation for geostrophic flows in the Southern Ocean. Nat. Geosci. 6 (1), 48-51, doi:10.1038/ngeo1657.

Okubo, A., 1970. Horizontal dispersion of floatable particles in vicinity of velocity singularities such as convergences. Deep-Sea Res. 17 (3), 445-454, doi:10.1016/0011-7471(70)90059-8.

Özgökmen, T. M., Fischer, P. F., Duan, J., Iliescu, T., 2004. Threedimensional turbulent bottom density currents from a high-order nonhydrostatic spectral element model. J. Phys. Oceanogr. 34 (9), 2006-2026, doi:10.1175/1520-0485(2004)034<2006:TTBDCF>2.0.CO;2.

Paschini, E., Artegiani, A., Pinardi, N., 1993. The mesoscale eddy field of the Middle Adriatic Sea during fall 1988. Deep Sea Res. 40 (7), 1365-1377.

Pickart, R. S., Spall, M. A., Ribergaard, M. H., Moore, G. W. K., Milliff, R. F. D., 2003. Deep convection in the Irminger Sea forced by the Greenland tip jet. Nature 424, 152-156, doi:10.1038/nature01729.

Pickart, R. S., Torres, D. J., Fratantoni, P. S., 2005. The East Greenland Spill Jet. J. Phys. Oceanogr. 35 (6), 1037-1053, doi:10.1175/JPO2734.1.

Poje, A. C., Haza, A. C., Özgökmen, T. M., Magaldi, M. G., Garraffo, Z. D., 2010. Resolution dependent relative dispersion statistics in a hierarchy of ocean models. Ocean Modell. 31 (1-2), doi:10.1016/j.ocemod.2009.09.002. 
Poulin, F. J., Swaters, G. E., 1999. Sub-inertial dynamics of density-driven flows in a continuously stratified fluid on a sloping bottom, II: isolated eddies and radiating cold domes. Proc. R. Soc. Lond. A 455, 2305-2329, doi:10.1098/rspa.1999.0405.

Ross, C. K., 1977. Overflow-73-Denmark Strait, vol. 2: Moored Instrument Time Series. Technical Report Data Series BI-D-77-5, Bedford Institute of Oceanography, Dartmouth, N.S., Canada, B2Y-4A2.

Rudels, B., 1986. The $\theta-s$ relations in the northern seas: implications for the deep circulation. Polar Res. 4 (2), 133-159, doi:10.1111/j.17518369.1986.tb00527.x.

Saunders, P. M., 2001. The dense northern overflows. In: Siedler, C., Gould, E. (Eds.), Ocean Circulation and Climate: Observing and Modelling the Global Ocean. Academic Pres, pp. 401-417.

Schroeder, K., Haza, A. C., Griffa, A., Özgökmen, T. M., Poulain, P.-M., Gerin, R., Peggion, G., Rixen, M., 2011. Relative dispersion in the LiguroProvençal basin: from sub-mesoscale to mesoscale. Deep-Sea Res. I 58 (3), 209-228, doi:10.1016/j.dsr.2010.11.004.

Scotti, A., Pineda, J., 2006. Observation of very large and steep internal waves of elevation near the Massachusetts coast. Geophys. Res. Lett. 31, L22307, doi:10.1029/2004GL021052.

Shapiro, G. I., Huthnance, J. M., Ivanov, V. V., 2003. Dense water cascading off the continental shelf. J. Geophys. Res. 108 (C12), 3390, doi:10.1029/2002JC001610. 
Spall, M. A., Price, J. F., 1998. Mesoscale variability in Denmark Strait: the PV outflow hypothesis. J. Phys. Oceanogr. 28 (8), 1598-1623, doi:10.1175/1520-0485(1998)028<1598:MVIDST>2.0.CO;2.

Steele, M., Morley, R., Ermold, W., 2001. PHC: a global ocean hydrography with a high-quality Arctic Ocean. J. Climate 14 (9), 2079-2087, doi:10.1175/1520-0442(2001)014<2079:PAGOHW>2.0.CO;2.

Swaters, G. E., Flierl, G. R., 1991. Dynamics of ventilated coherent cold eddies on a sloping bottom. J. Fluid Mech. 223, 565-587, doi:10.1017/S0022112091001556.

Tessler, Z. D., Gordon, A. L., 2012. Early stage soliton observations in the Sulu Sea. J. Phys. Oceanogr. 42 (8), 1327-1336, doi:10.1175/JPO-D-110165.1.

Theocharis, A., Georgopoulos, D., 1993. Dense water formation over the Samothraki and Limnos Plateaux in the North Aegean Sea (Eastern Mediterranean Sea). Cont. Shelf Res. 13 (8-9), 919-939, doi:1016/02784343(93)90017-R.

Thorpe, S. A., 2005. The Turbulent Ocean. Cambridge University Press, 439 pp.

Våge, K., Pickart, R. S., Spall, M. A., Valdimarsson, H., Jónsson, S., Torres, D. J., Østerhus, S., Eldevik, T., 2011. Significant role of the North Icelandic Jet in the formation of Denmark Strait overflow water. Nat. Geosci 4 (10), 723-727, doi:10.1038/ngeo1234. 
Vilibić, I., Supić, N., 2005. Dense water generation on a shelf: the case of the Adriatic Sea. Ocean Dyn. 55 (5-6), 403-415, doi:10.1007/s10236-005$0030-5$.

von Appen, W.-J., Koszalka, I. M., Pickart, R. S., Haine, T. W. N., Mastropole, D., Magaldi, M. G., Valdimarsson, H., Girton, J., Jochumsen, K., Krahmann, G., 2014a. The East Greenland Spill Jet as an important component of the Atlantic Meridional Overturning Circulation. Deep Sea Res. I 92, 75-84, doi:10.1016/j.dsr.2014.06.002.

von Appen, W.-J., Pickart, R. S., Brink, K. H., Haine, T. W. N., 2014 b. Water column structure and statistics of Denmark Strait Overflow Water cyclones. Deep Sea Res. I 84, 110-126, doi:10.1016/j.dsr.2013.10.007.

Wadzuk, B., Hodges, B., 2009. Hydrostatic versus nonhydrostatic Eulerequation modeling of nonlinear internal waves. J. Eng. Mech. 135 (10), 1069-1080, doi:10.1061/(ASCE)0733-9399(2009)135:10(1069).

Weiss, J., 1991. The dynamics of enstrophy transfer in two-dimensional hydrodynamics. Physica D: Nonlinear Phenom. 48 (2-3), 273-294, doi:10.1016/0167-2789(91)90088-Q.

Whitehead, J. A., 1987. Dense water off continents. Nature 327 (6124), 656, doi:10.1038/327656a0.

Whitehead, J. A., Stern, M. E., Flierl, G. R., Klinger, B. A., 1990. Experimental observations of baroclinic eddies on a sloping bottom. J. Geophys. Res. 95 (C6), 9585-9610, doi:10.1029/JC095iC06p09585. 
Winters, K. B., Lombard, P. N., Riley, J. J., D'Asaro, E. A., 1995. Available potential energy and mixing in density-stratified fluids. J. Fluid Mech. 289, 115-128, doi:10.1017/S002211209500125X.

Zhang, H.-M., Bates, J. J., Reynolds, R. W., 2006. Assessment of composite global sampling: sea surface wind speed. Geophys. Res. Lett. 33 (17), L17714, doi:10.1029/2006GL027086. 
(a) $P$, Hydr. 2km, large domain

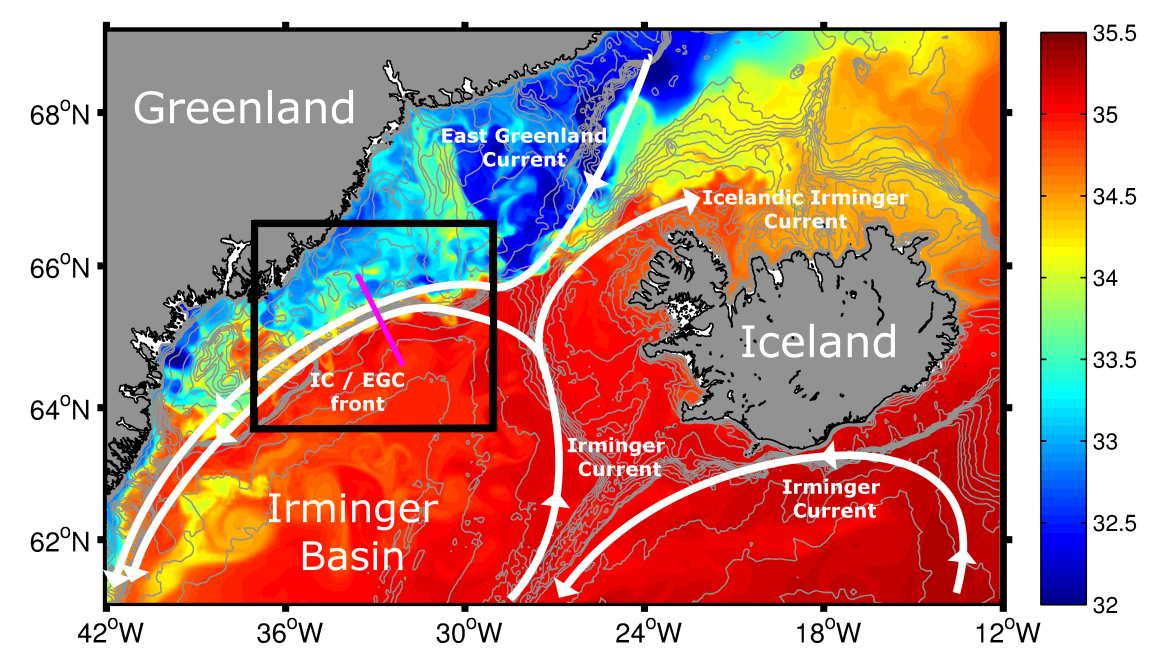

(b) $P$, Hydr. 2km, closeup

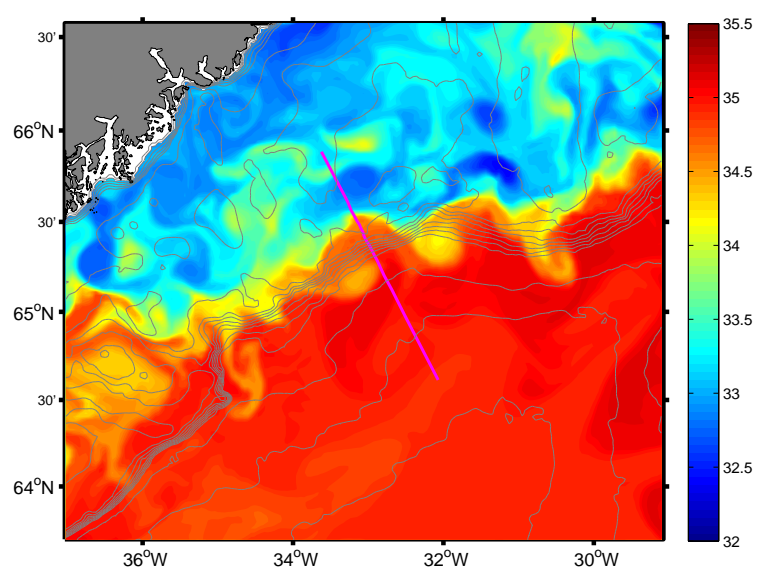

(c) $C_{h}$, Hydr. $500 \mathrm{~m}$

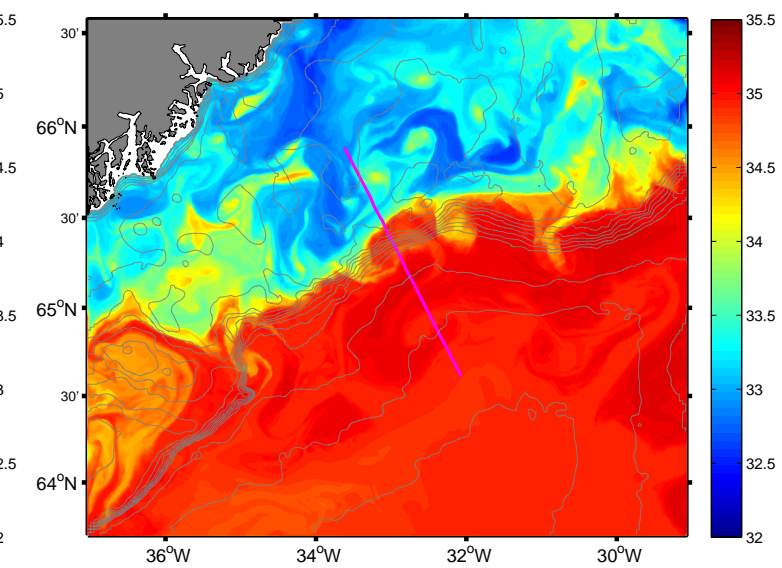

(d) $C_{n}$, Non-Hydr. $500 \mathrm{~m}$

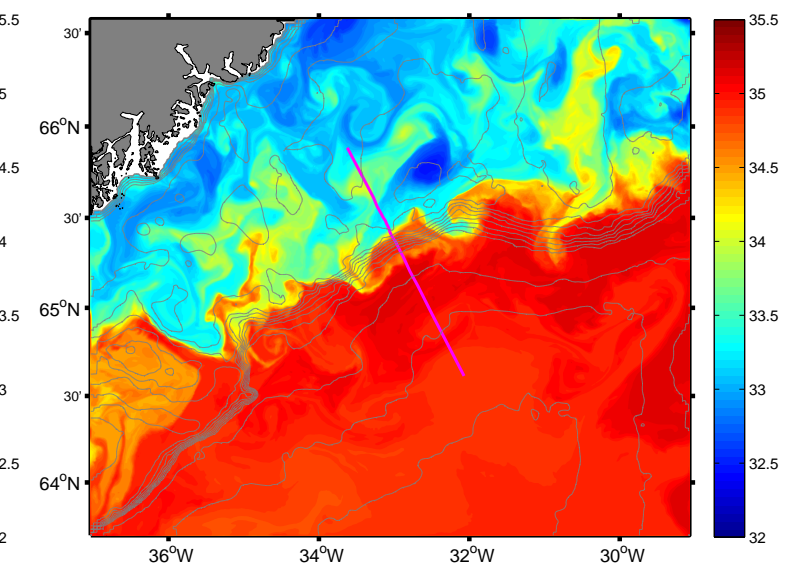

Figure 1: Plan view of the numerical domains showing the sea surface salinity field on 19 July, 1800 UTC. The 20, 40, 60, 80, $100,200,300,400,500,600,700,800,1000,1500,2000$, and 2500-m isobaths are in gray. The Spill Jet line is in magenta. a) Large domain for the 2-km, hydrostatic parent $(P)$ run. The black box denotes the boundaries for the closeup in b) and the child grid. b) Closeup around the Spill Jet line for the $P$ run. c) Domain for the 0.5-km hydrostatic child $\left(C_{h}\right)$ run. d) As in c) but for the $0.5-\mathrm{km}$ non-hydrostatic child $\left(C_{n}\right)$ run. 
(a) 9 August, 1800 UTC

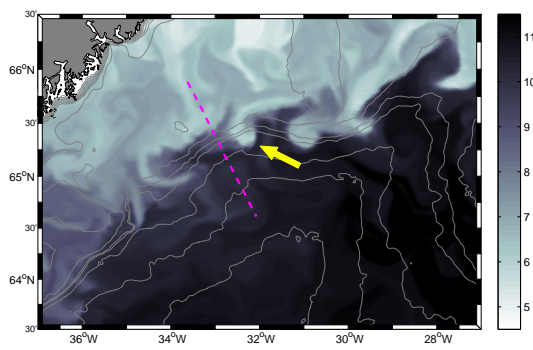

(d)

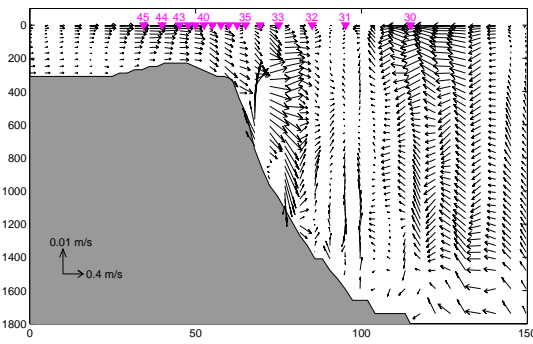

$(\mathrm{g})$

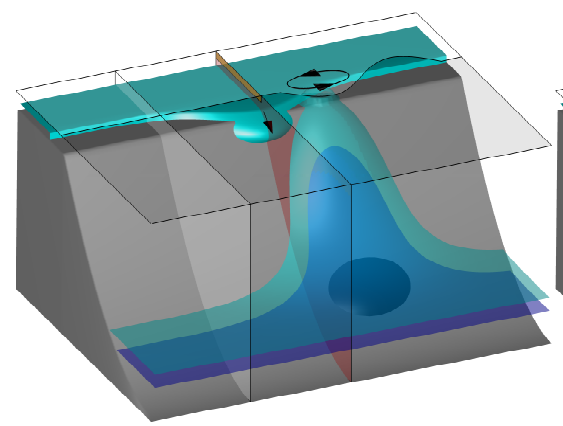

(b) 10 August, 0600 UTC

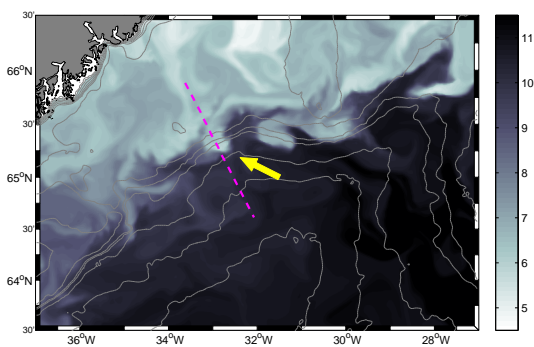

(e)

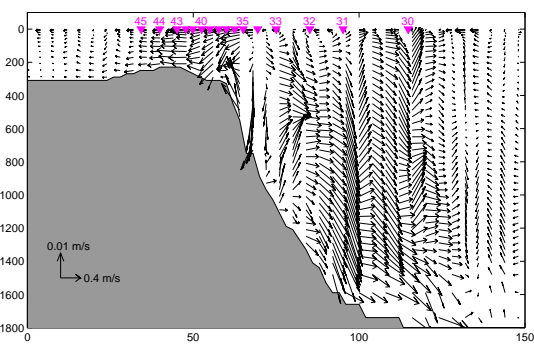

(h)

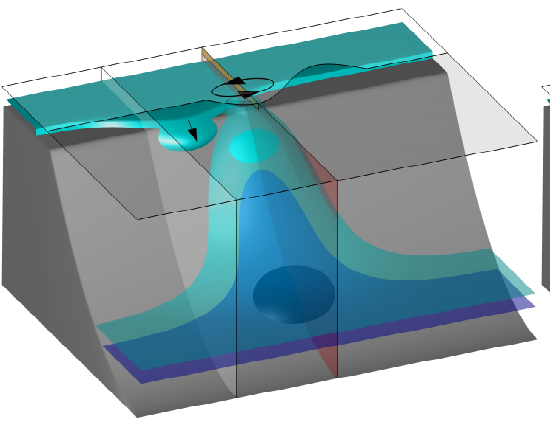

(c) 10 August, 1800 UTC

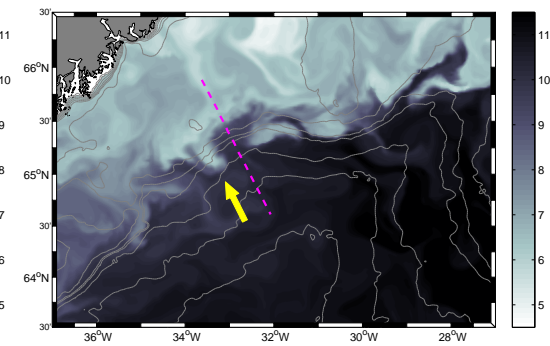

(f)

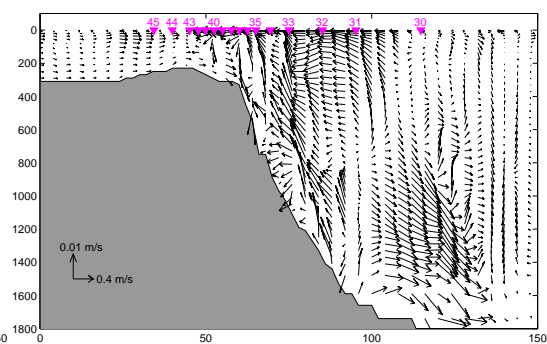

(i)

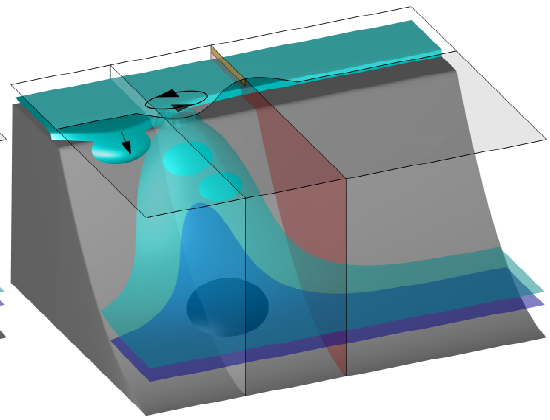

Figure 2: The eddy-induced cascading process according to Magaldi et al. (2011). Upper panels: Sequence of sea-surface temperature $\left({ }^{\circ} \mathrm{C}\right.$ ) images in the parent $P$ simulation (a frame every 12 hours). The yellow arrow shows a cyclone moving along the edge of the continental shelf. As its leading edge approaches the Spill Jet line, it draws dense shelf water offshore and initiates the spilling. Middle panels: Corresponding model cross-stream lateral circulation at the Spill Jet section. Downward (upward) intense motion is associated with the leading (trailing) edge of the cyclone. Lower panels: Schematic view of the process: The continental shelf is the shallow part at the top of each frame. The magenta plane is the Spill Jet section. The cyan and violet surfaces are sheets of constant density (violet is denser and deeper). For details refer to Magaldi et al. (2011) noting that panels (b)-(c) and (e)-(f) are new and allow a visual comparison between different phases of the process. 
(a) $v_{n}$ and $\sigma_{\theta}, P$, Hydr. $2 \mathrm{~km}$

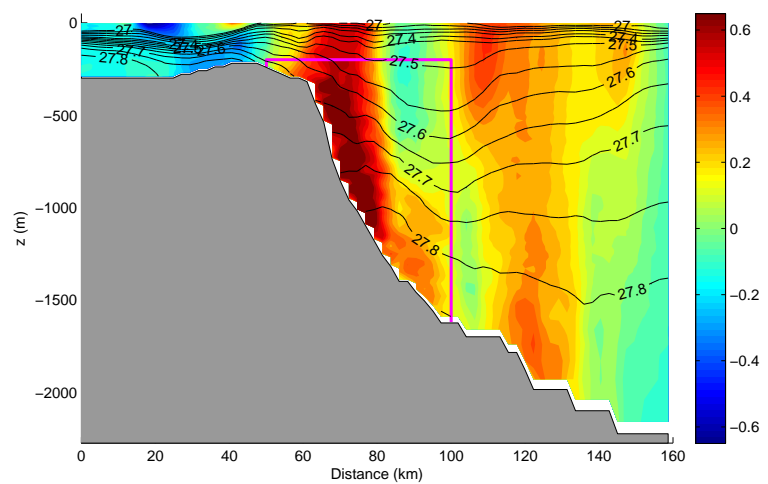

(d) $\bar{w}$ and $\overline{\sigma_{\theta}}, P$, Hydr. $2 \mathrm{~km}$

$\underset{\infty}{\infty}$

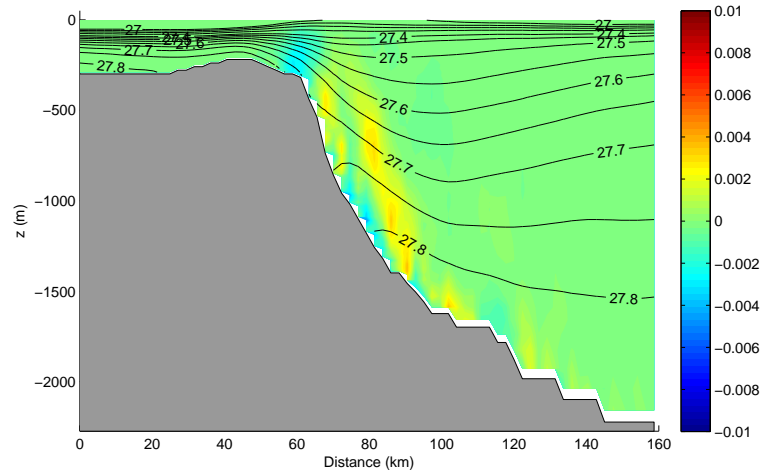

(b) $v_{n}$ and $\sigma_{\theta}, C_{h}$, Hydr. $500 \mathrm{~m}$

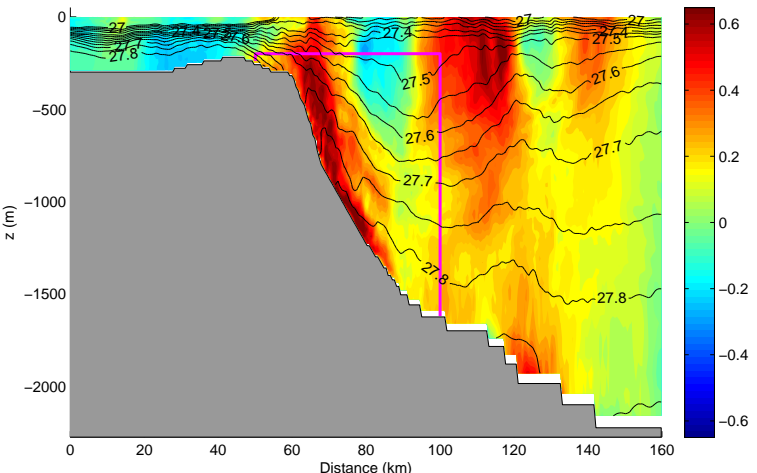

(e) $\bar{w}$ and $\overline{\sigma_{\theta}}, C_{h}$, Hydr. $500 \mathrm{~m}$

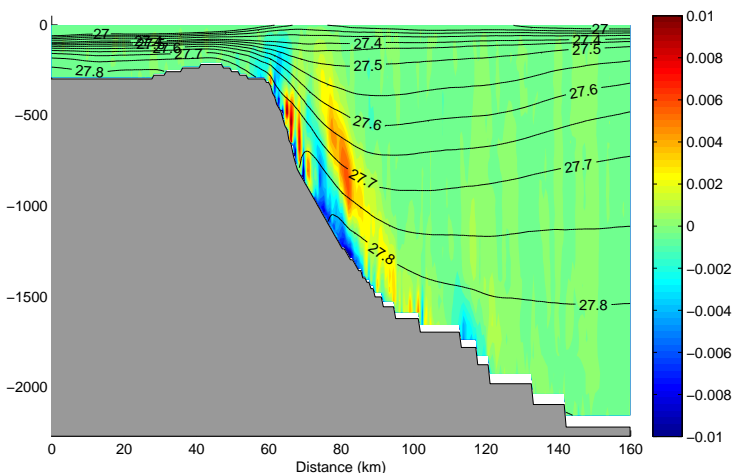

(c) $v_{n}$ and $\sigma_{\theta}, C_{n}$, Non-Hydr. $500 \mathrm{~m}$

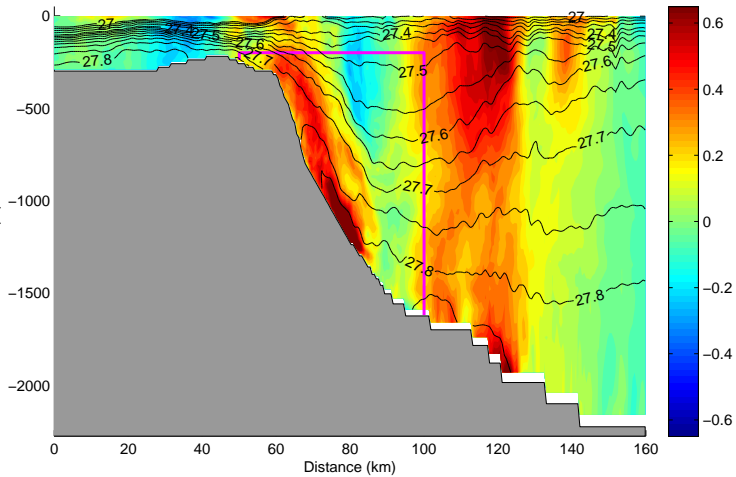

(f) $\bar{w}$ and $\overline{\sigma_{\theta}}, C_{n}$, Non-Hydr. $500 \mathrm{~m}$

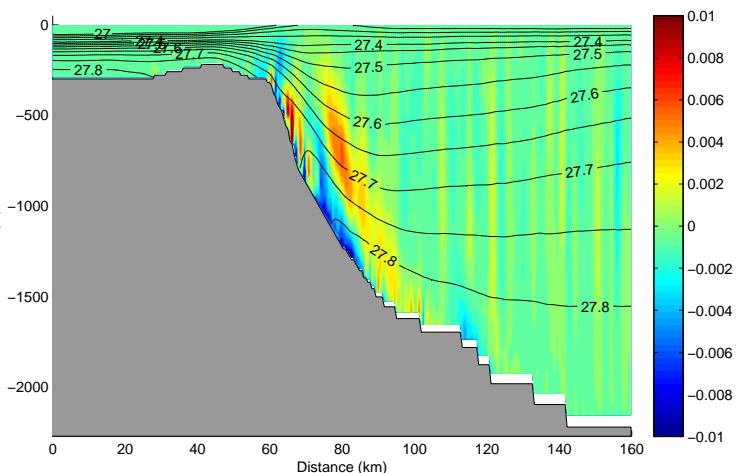

Figure 3: Upper panels: along-stream velocities $v_{n}\left(\mathrm{~m} \mathrm{~s}^{-1}\right.$, color) normal to the Spill Jet line and potential density contours $\sigma_{\theta}$ ( $\mathrm{kg} \mathrm{m}^{-3}$, black lines) on 19 July, 1800 UTC. Positive $v_{n}$ values stand for equatorward flow. Lower panels: time-averaged vertical velocities $\bar{w}\left(\mathrm{~m} \mathrm{~s}^{-1}\right.$, color) and time-averaged potential density contours $\overline{\sigma_{\theta}}\left(\mathrm{kg} \mathrm{m}^{-3}\right.$, black lines) at the Spill Jet line. Positive (negative) values are for upward (downward) vertical velocities. The magenta box is the region used to calculate volume transports for the Spill Jet (see text). 
(a)

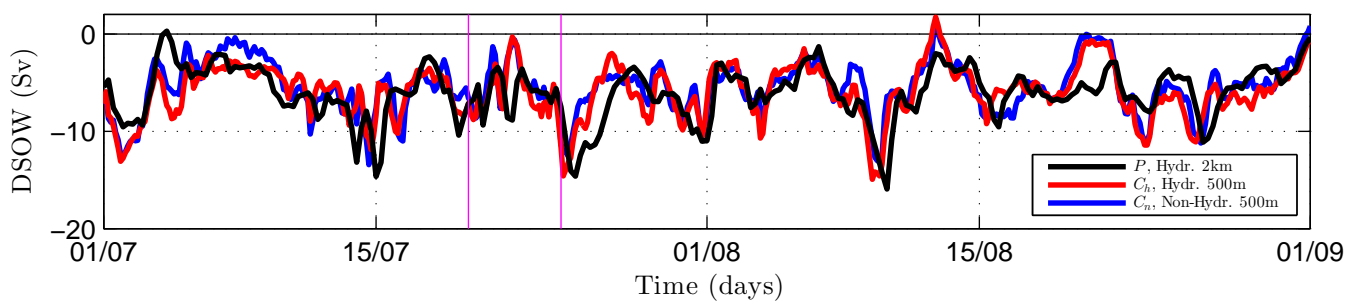

(b)

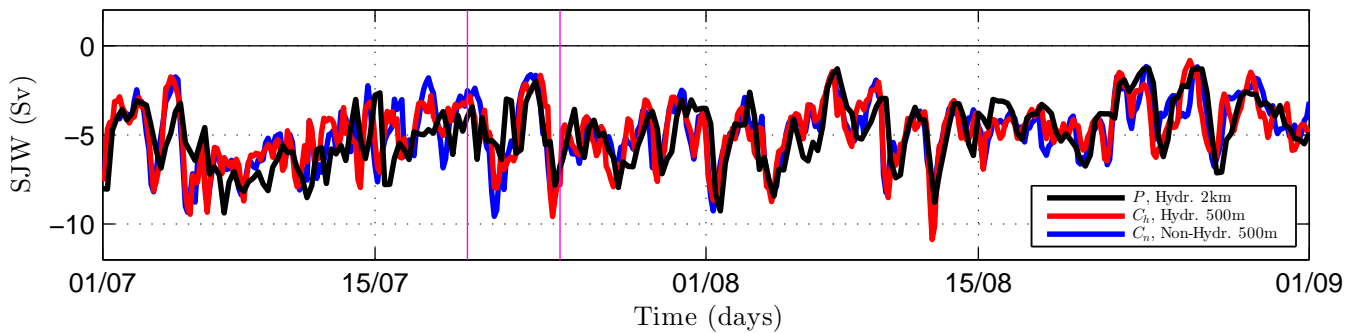

Figure 4: Time evolution for the volume transport (in Sv) of (a) Denmark Strait Overflow and (b) Spill Jet waters at the Spill Jet line in the three runs. Negative values stand for equatorward transports. The magenta vertical lines indicate the times July 19, 1800 UTC and July 24, 1200 UTC used in other figures. Transport values are calculated according to the $Q_{2}$ definition in MHP11. 


\section{$C_{b c}=-\int g \overline{\rho / w^{\prime}} d z$}
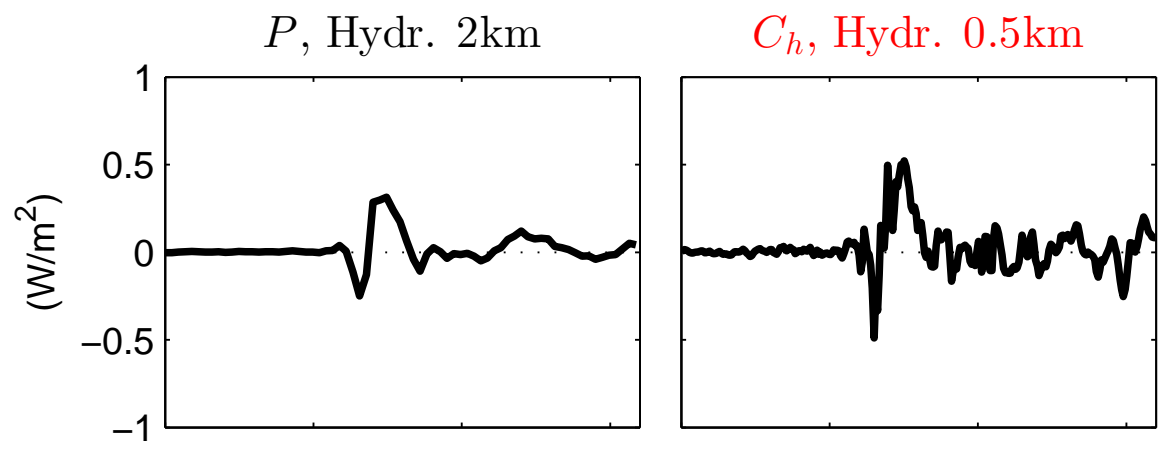

$C_{n}$, Non-Hydr. $0.5 \mathrm{~km}$
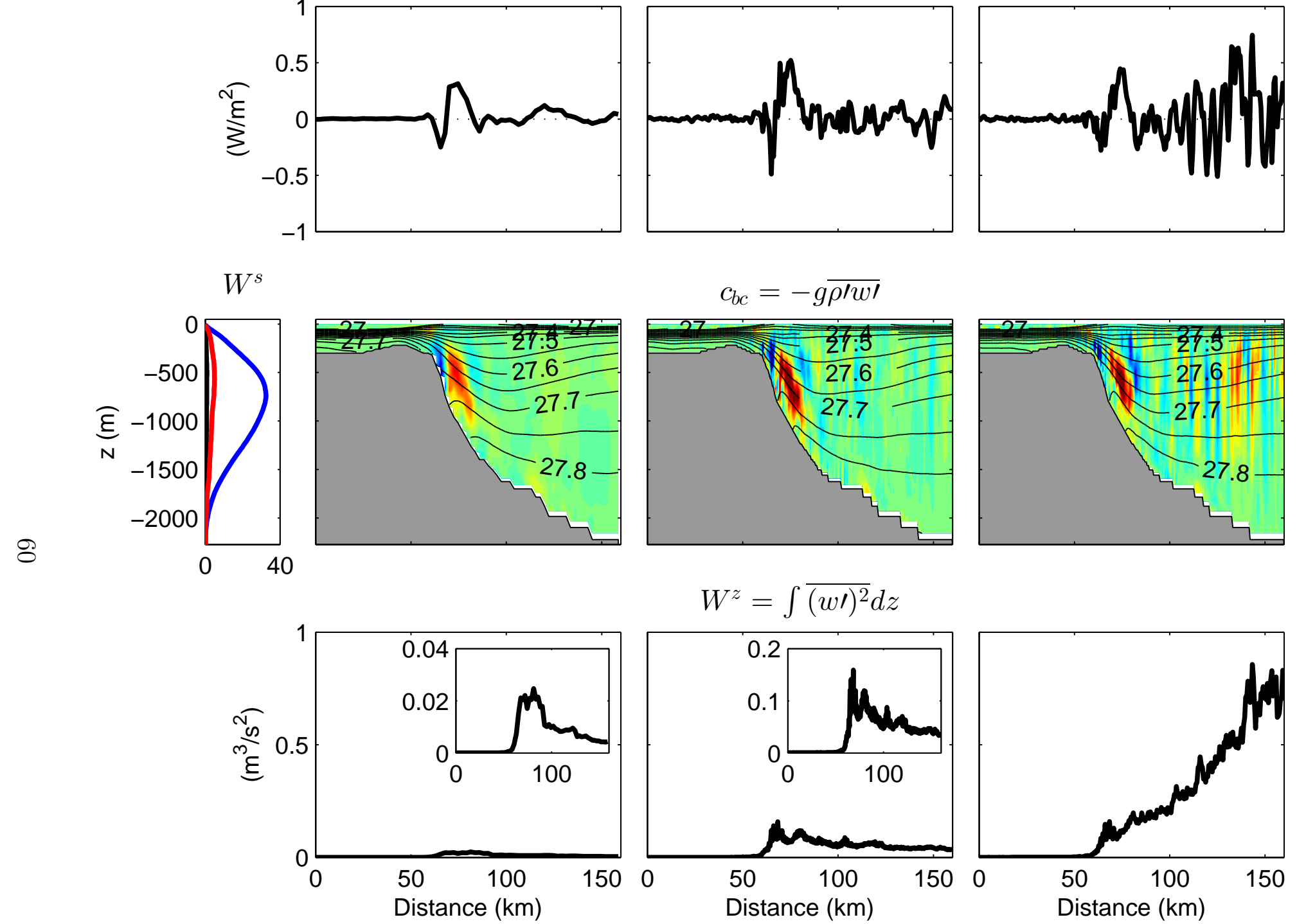

Figure 5: Baroclinic conversion terms and vertical eddy kinetic energy for the three runs at the Spill Jet line. Upper panels: vertically-integrated baroclinic conversion term $C_{b c}=\int c_{b c} d z$ as a function of distance, $s$, at the Spill Jet line. Middle panels: baroclinic conversion term $c_{b c}$ (color) and time-averaged potential density contours $\overline{\sigma_{\theta}}$ (black lines) at the Spill Jet line. Lower panels: vertically-integrated vertical eddy kinetic energy $W^{z}=\int \overline{(w /)^{2}} d z$ as a function of distance at the Spill Jet line. Insets show the same curves with different $y$-axis limits. Leftmost middle panel: horizontally-integrated vertical eddy kinetic energy $W^{s}=\int \overline{(w /)^{2}} d s$ as a function of depth. Black, red and blue colors stand for the $P, C_{h}$ and $C_{n}$ runs, respectively. 
(a)

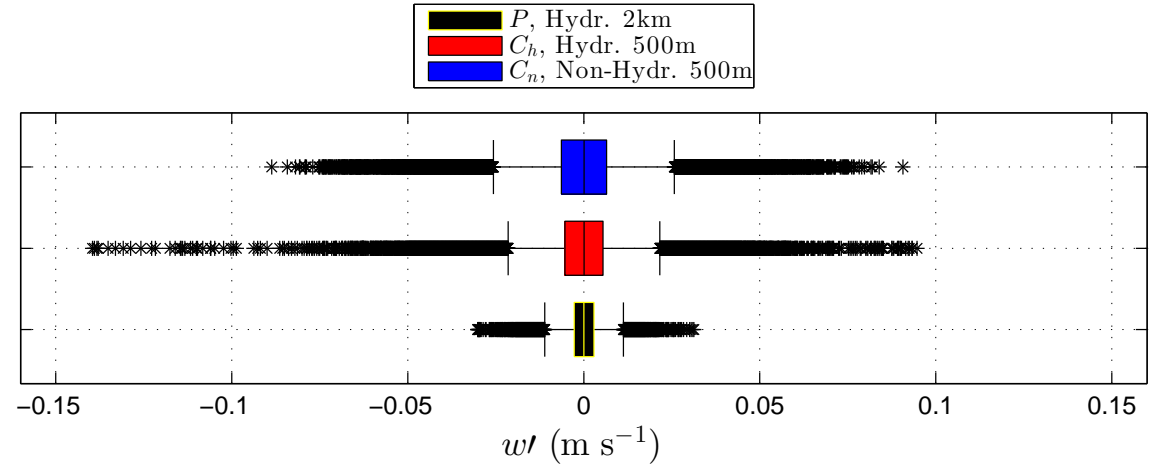

(b)

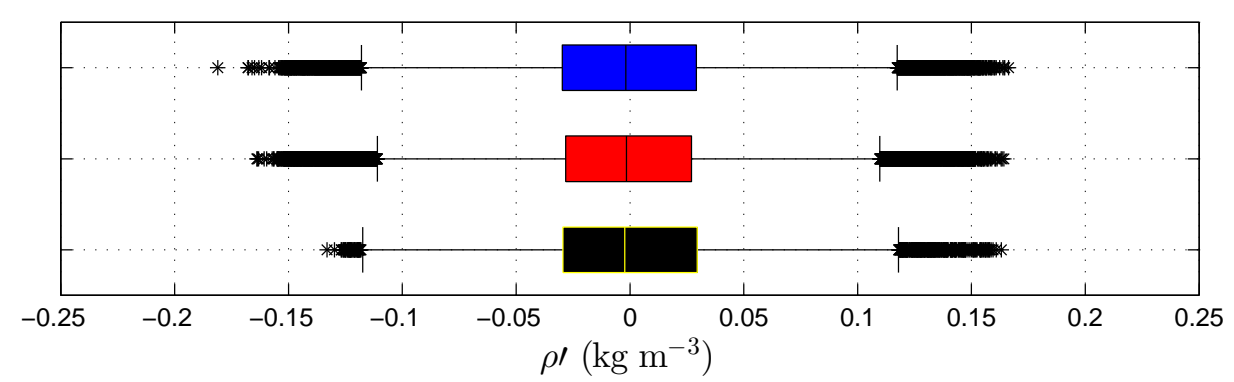

Figure 6: Boxplots for $w^{\prime}$ (top panel) and $\rho$ (bottom panel) distributions in the positive $c_{b c}$ area close to the slope for the three runs (see Fig. 5). Boxplots are constructed in order to have approximately \pm 2.7 std and $99.3 \%$ coverage between the two whiskers, where with "std" we indicate the standard deviation of the distribution. Box lines indicate first, second and third quartiles, respectively. Outlier values are indicated with black asterisks. 


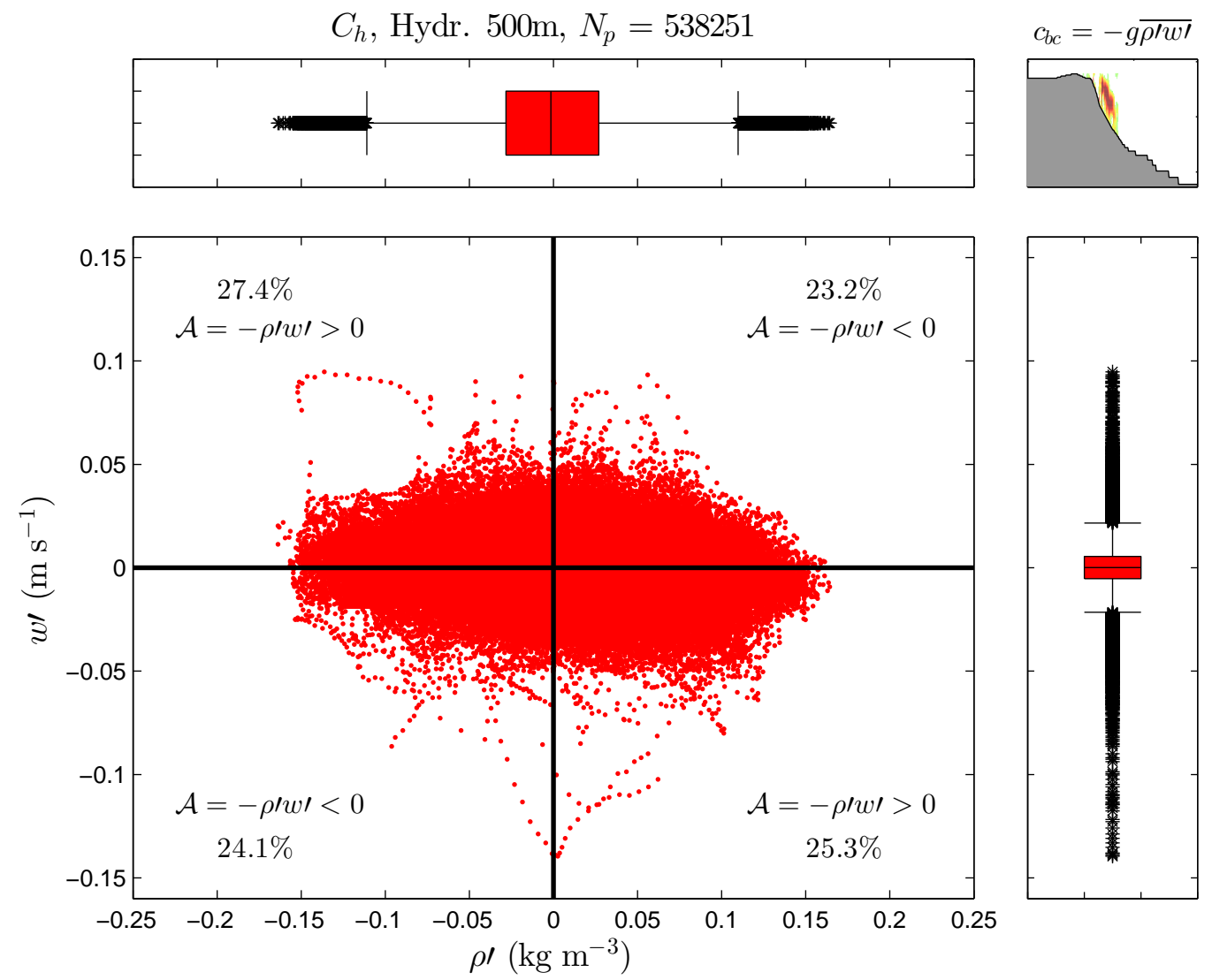

Figure 7: Scatter and box plots for the $\rho /$ and $w \prime$ distributions for $c_{b c}>0$ points near the slope in the $C_{h}$ run (see Figs. 5 and 6 ). The top right panel shows which points in the section are selected, $N_{p}$ indicates their number. $\mathcal{A}=-\rho / w /$ indicates the sign of the contributions to $c_{b c}$ in each quadrant. 
(a) $w\left(\mathrm{~m} \mathrm{~s}^{-1}\right), P$, Hydr. $2 \mathrm{~km}$

(b) $w\left(\mathrm{~m} \mathrm{~s}^{-1}\right), C_{h}$, Hydr. $500 \mathrm{~m}$
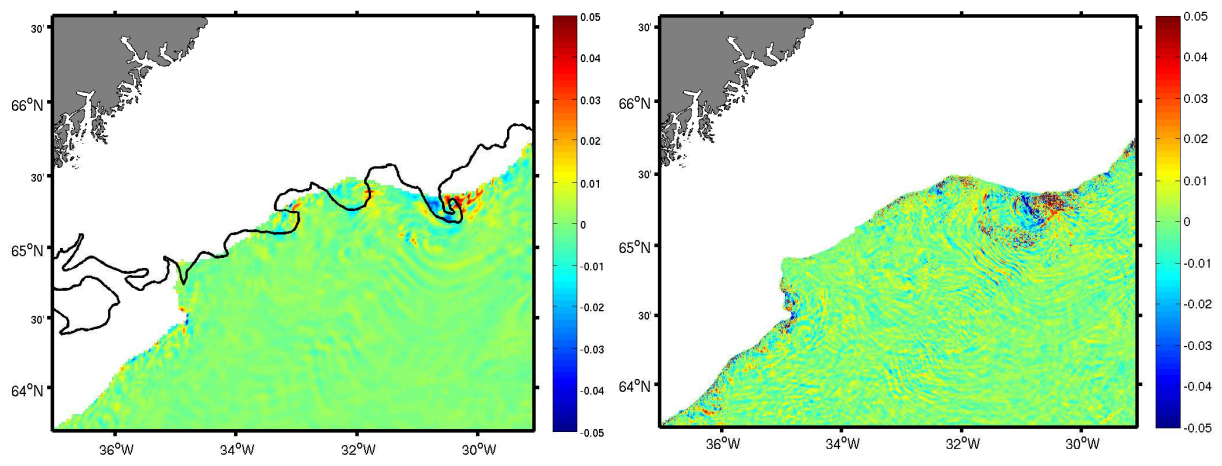

(c) $w\left(\mathrm{~m} \mathrm{~s}^{-1}\right), C_{n}$, Non-Hydr. $500 \mathrm{~m}$

(d) $\tilde{w}\left(\mathrm{~m} \mathrm{~s}^{-1}\right), C_{n}$, Non-Hydr. $500 \mathrm{~m}$
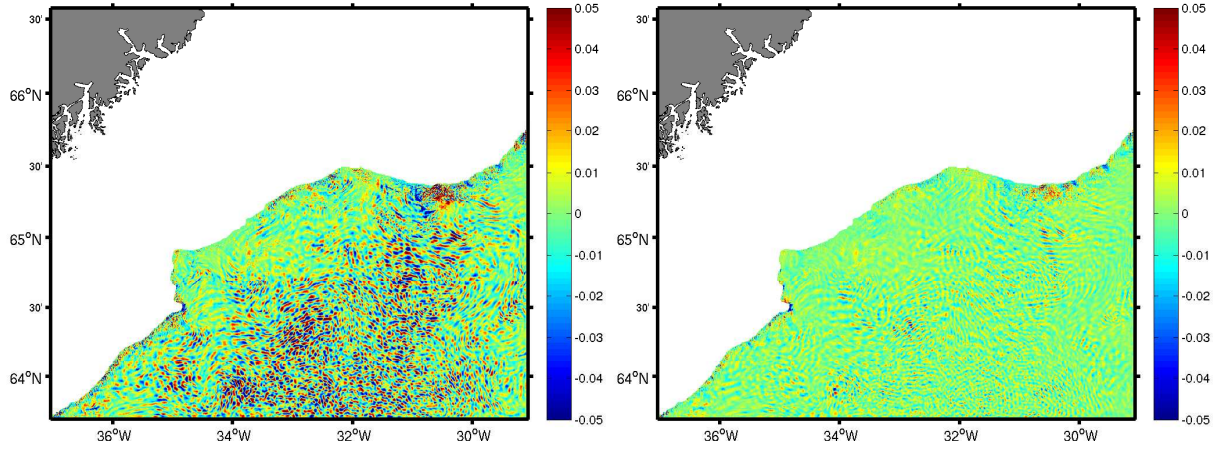

Figure 8: (a)-(c) Vertical velocity fields in the three runs at $719 \mathrm{~m}$ depth on 19 July, 1800 UTC. (d) As (c) but after applying a 15h-running mean. The colorbar in the figure is different from the one used in Animation 2 for the $P$ run. The black line in (a) indicates the same $8{ }^{\circ} \mathrm{C}$ sea surface temperature contour as in Fig. 10a. 


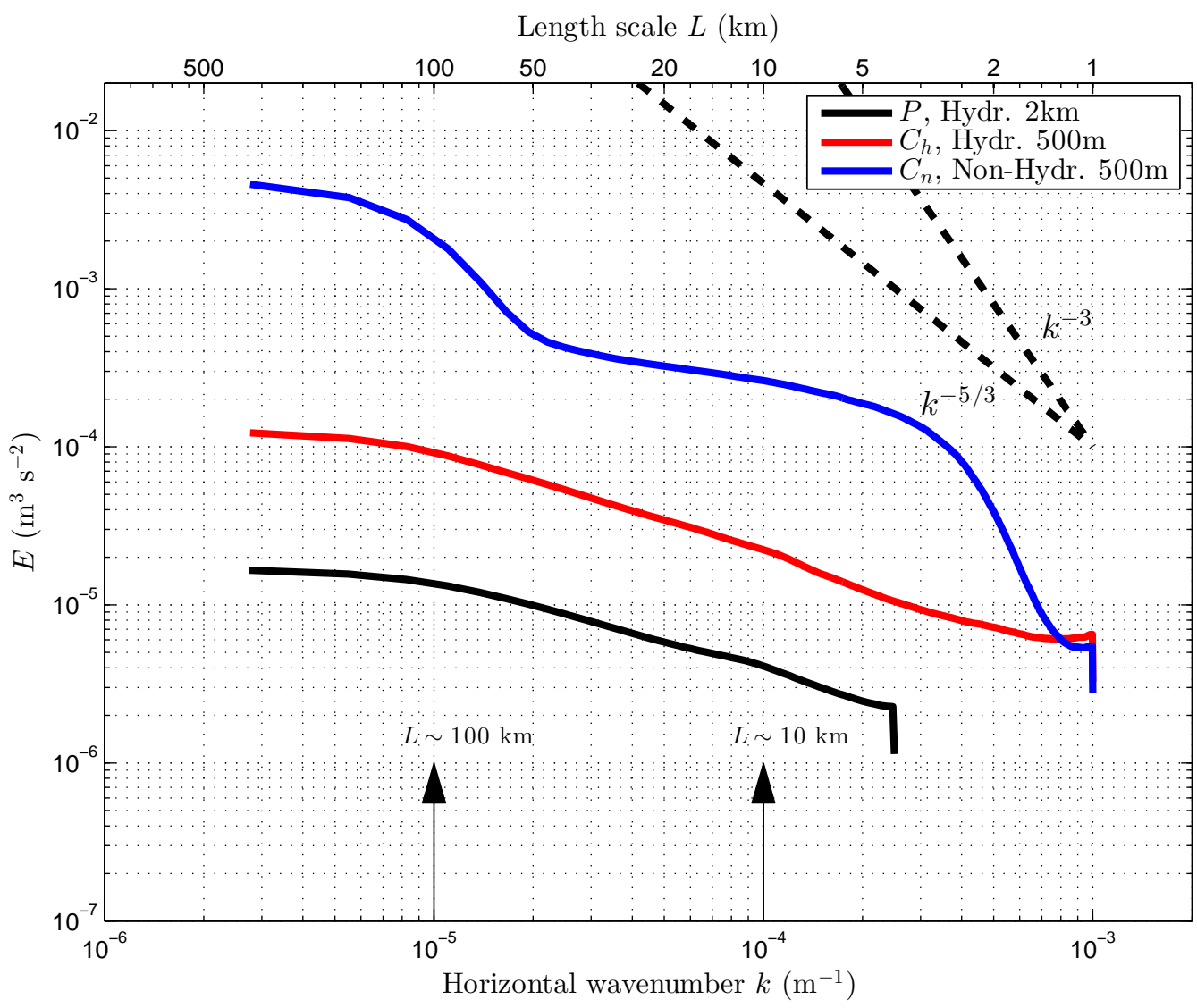

Figure 9: Time-averaged vertical kinetic energy spectra at $719 \mathrm{~m}$ depth. Dashed lines indicate the $k^{-5 / 3}$ and $k^{-3}$ slopes. 
(a) $\operatorname{SST}\left({ }^{\circ} \mathrm{C}\right), P$, Hydr. $2 \mathrm{~km}$

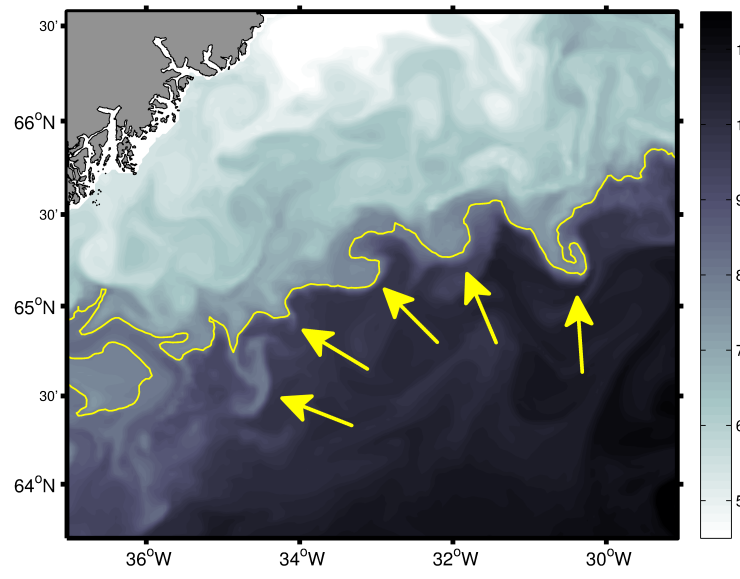

(d) $\xi \times 10^{-4}\left(\mathrm{~s}^{-1}\right), P$, Hydr. $2 \mathrm{~km}$

or (b) $\operatorname{SST}\left({ }^{\circ} \mathrm{C}\right), C_{h}$, Hydr. $500 \mathrm{~m}$

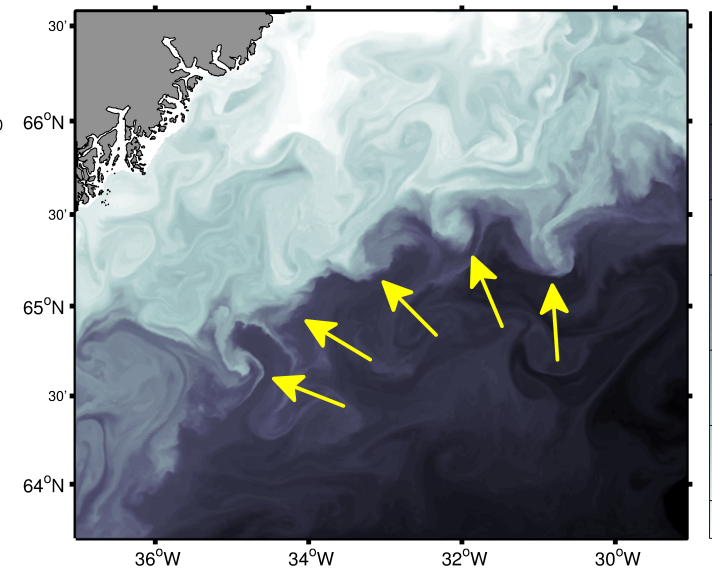

(e) $\xi \times 10^{-4}\left(\mathrm{~s}^{-1}\right), C_{h}$, Hydr. $500 \mathrm{~m}$

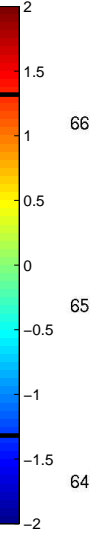

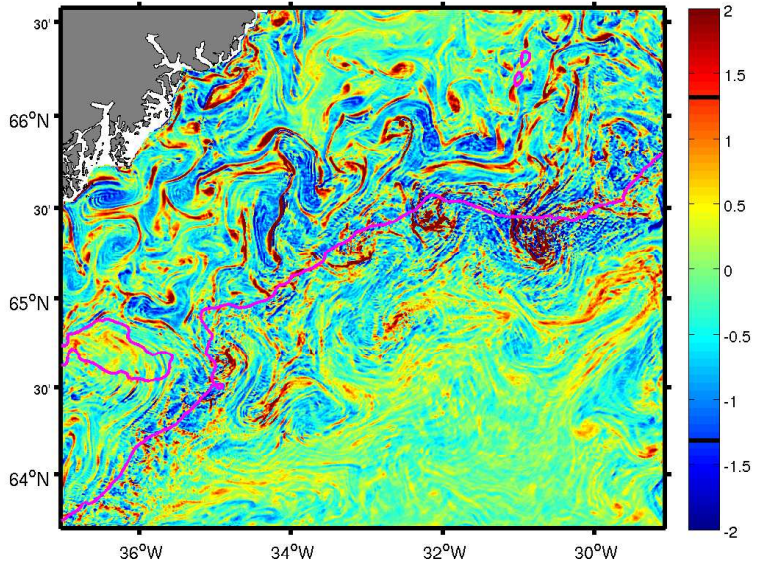

$32^{\circ} \mathrm{W}$ (c) $\operatorname{SST}\left({ }^{\circ} \mathrm{C}\right), C_{n}$, Non-Hydr. $500 \mathrm{~m}$

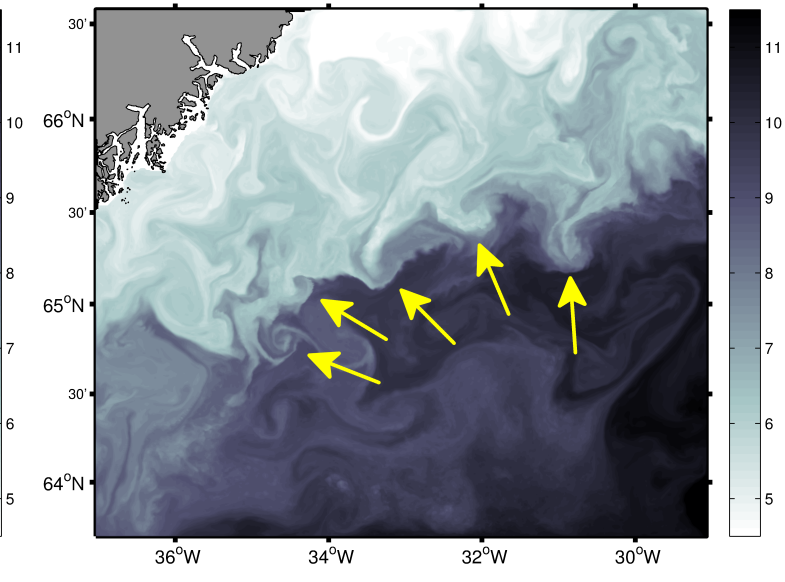

(f) $\xi \times 10^{-4}\left(\mathrm{~s}^{-1}\right), C_{n}$, Non-Hydr. $500 \mathrm{~m}$

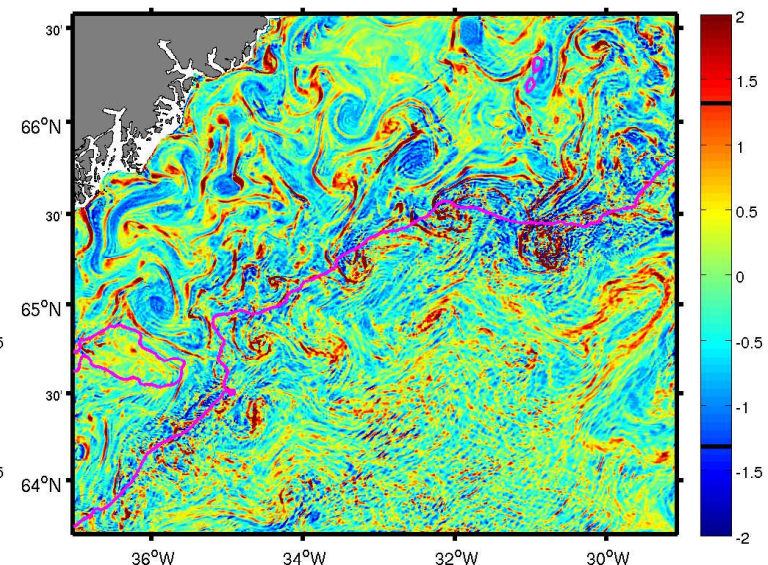

Figure 10: (a)-(c) Sea surface temperature, (d)-(f) vorticity and (g)-(i) strain fields on 19 July, 1800 UTC. The yellow line in (a) indicates the $8{ }^{\circ} \mathrm{C}$ sea surface temperature contour. The yellow arrows in (a)-(c) show five cyclones moving along the shelfbreak. The black lines in the colorbars of (d)-(f) indicate the $\pm \xi / f=1$ values. The $500 \mathrm{~m}$ isobath is in magenta in (d)-(i) for reference. 
(g) $S^{2} \times 10^{-8}\left(\mathrm{~s}^{-2}\right), P$, Hydr. $2 \mathrm{~km}$

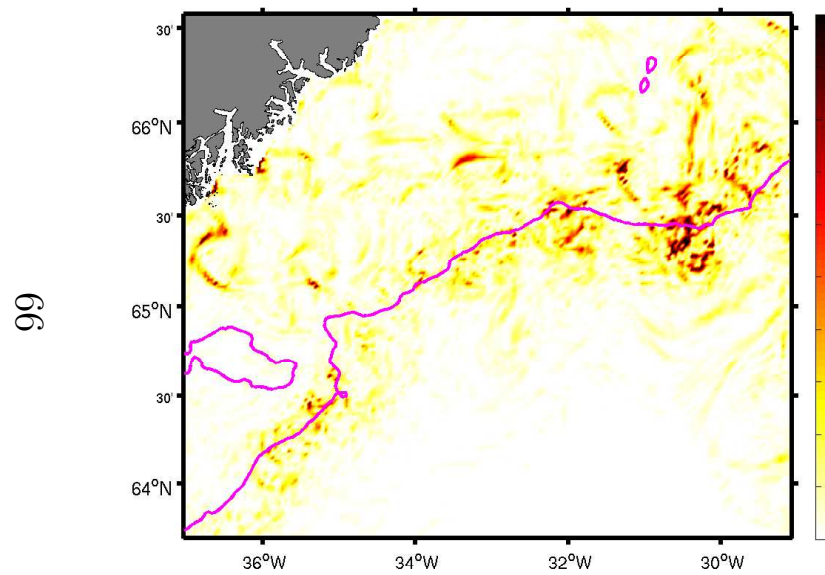

(h) $S^{2} \times 10^{-8}\left(\mathrm{~s}^{-2}\right), C_{h}$, Hydr. $500 \mathrm{~m}$

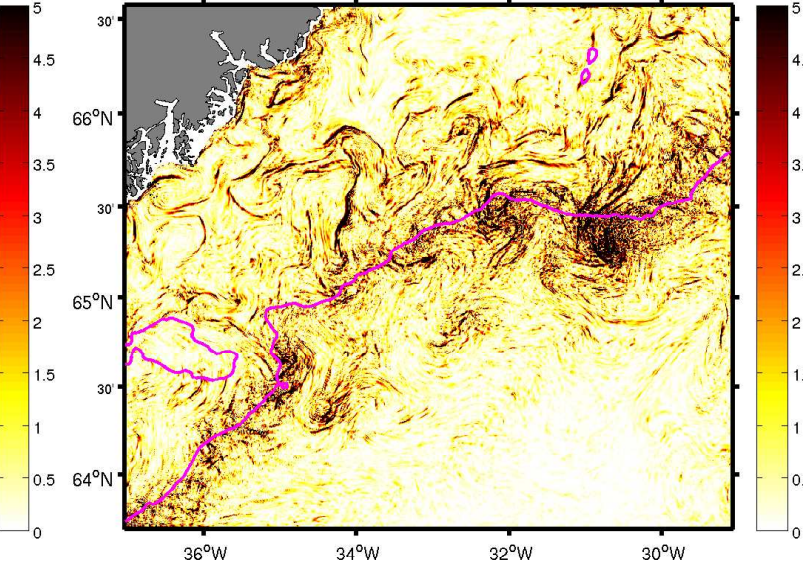

(i) $S^{2} \times 10^{-8}\left(\mathrm{~s}^{-2}\right), C_{n}$, Non-Hydr. $500 \mathrm{~m}$

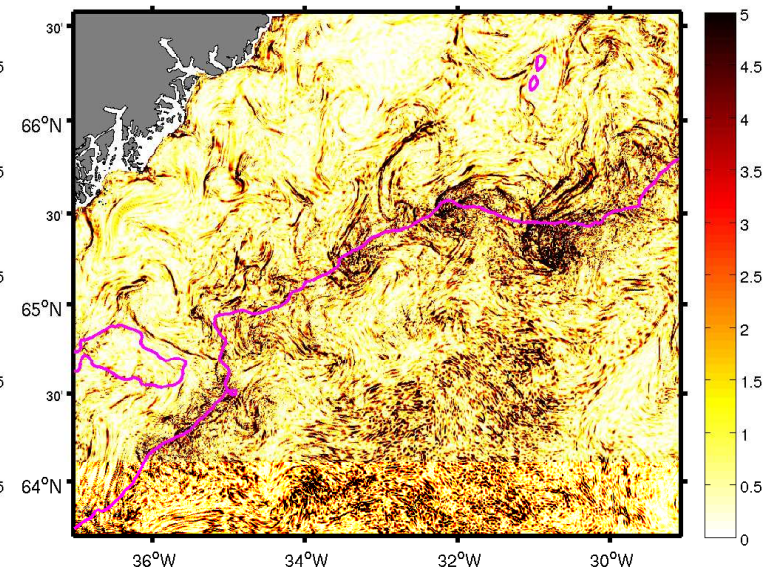

Figure 10: continued 


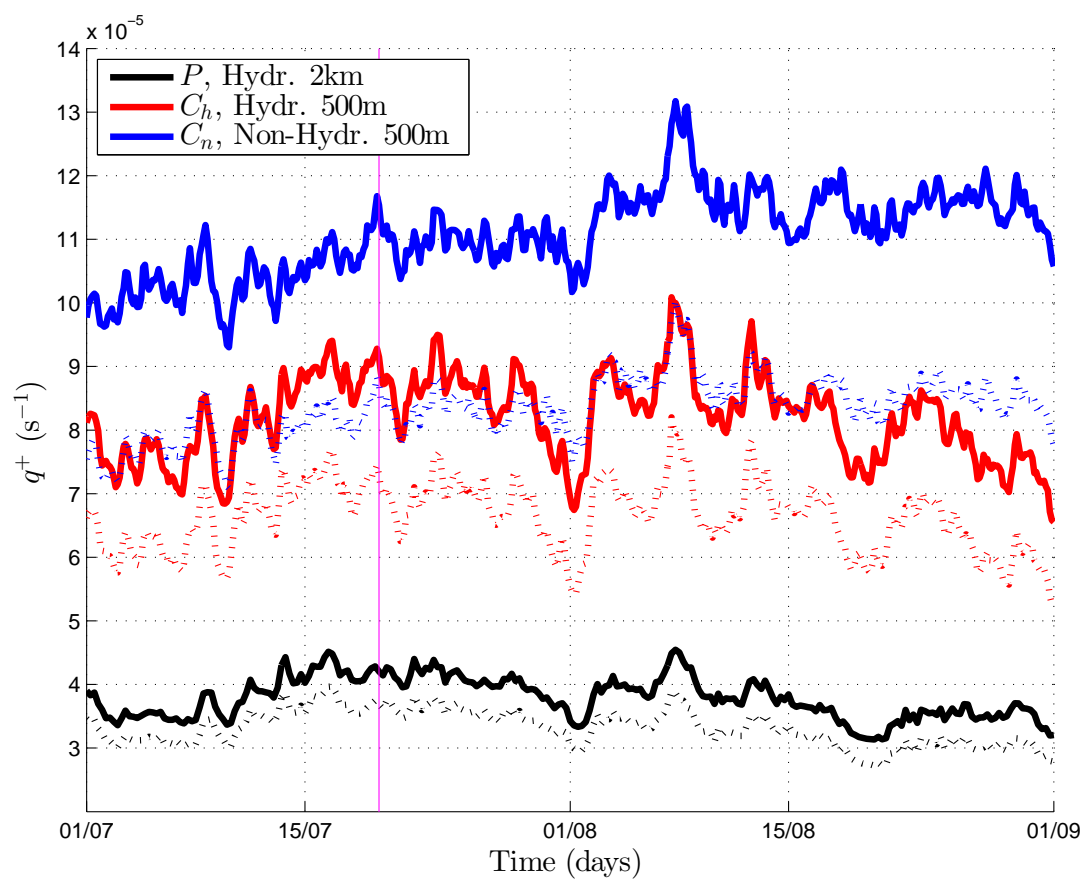

Figure 11: Time evolution for $q^{+}\left(\mathrm{s}^{-1}\right.$; see Eq. (2)) in the three runs. The solid (dotted) lines indicate calculations with (without) horizontal divergence. The magenta vertical line indicates the time July 19, 1800 UTC. 


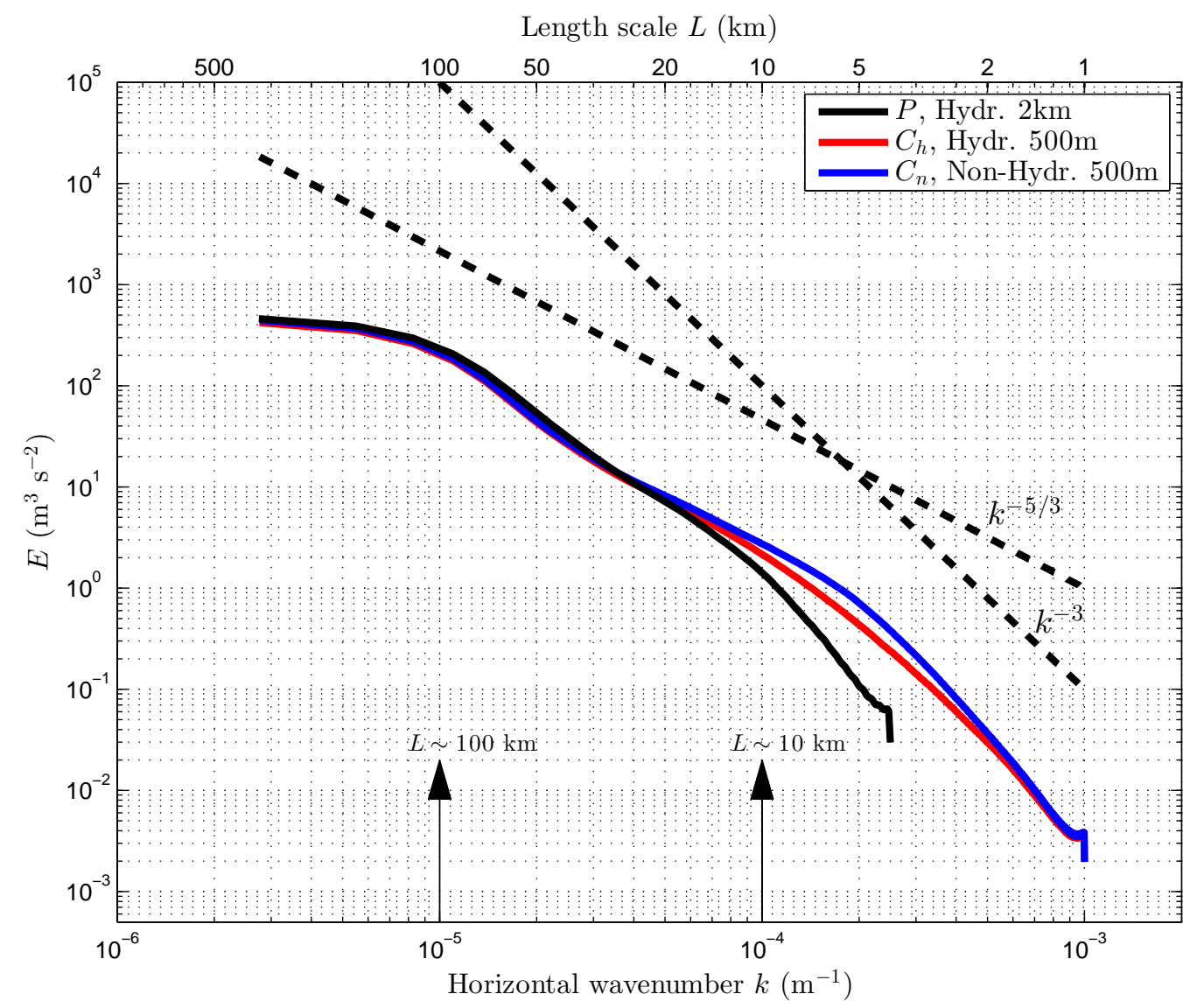

Figure 12: Surface kinetic energy spectra $E(k)$ averaged in time. Dashed lines indicate the $k^{-5 / 3}$ and $k^{-3}$ slopes. 

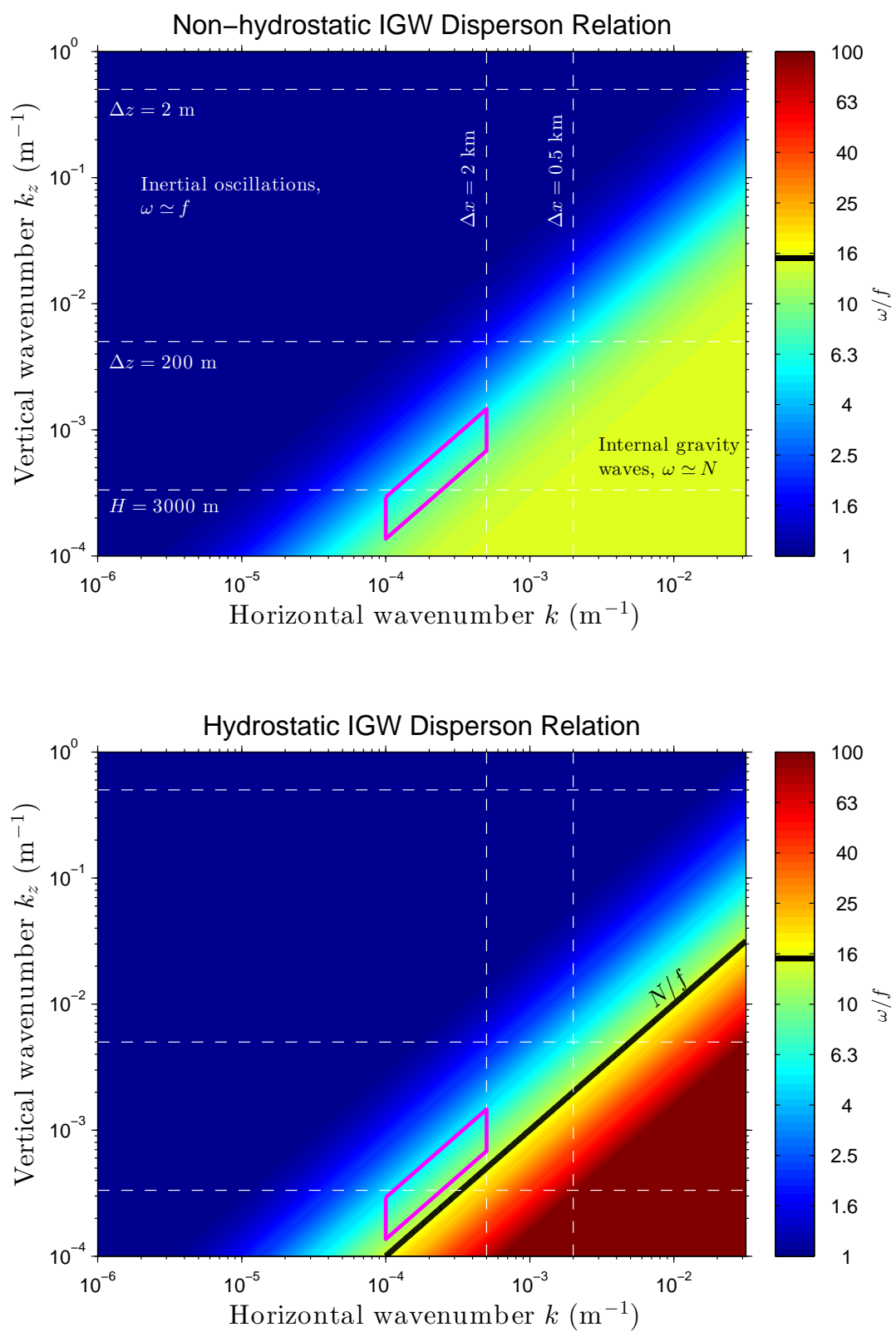

Figure 13: Comparison between non-hydrostatic (top) and hydrostatic (bottom) linear IGW dispersion relations, Eqs. (3) and (4). Colors show $\omega / f$ as a function of horizontal and vertical wavenumbers $k$ and $k_{z}$. The white dashed lines indicate the approximate maximum depth $H$ in the area common to all simulations and the maximum and minimum resolutions $(\Delta x, \Delta z)$ used in the three runs. For clarity values are indicated only in the top panel. The black lines in the colorbars and bottom panel indicate the $N / f$ value. The magenta box indicates the $2 \mathrm{~km}<L<10 \mathrm{~km}$ and $5 f<\omega<9 f$ ranges from Figs. 9 and 14 where extra energy is found in the non-hydrostatic run. The linear dispersion relations assume infinite-depth constant $N$ ocean: they are most accurate for large $k_{z}$. 


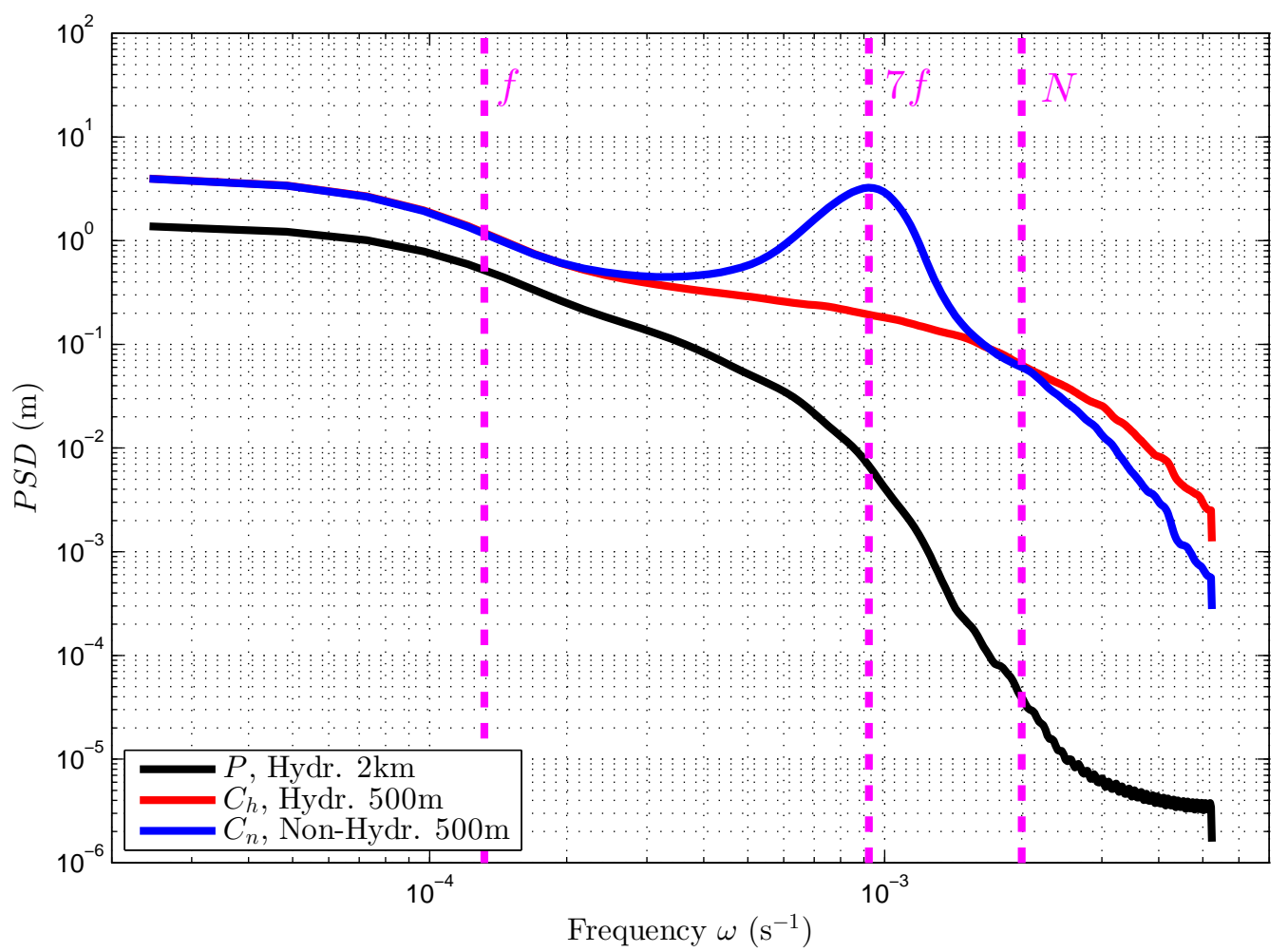

Figure 14: Spatially-averaged spectral density of vertical speeds in the three runs at $719 \mathrm{~m}$ depth during 1 July, 0000 UTC to 4 July, 0000 UTC. The magenta dashed lines indicate (from left to right) the inertial $f \simeq 1.3 \times 10^{-4} \mathrm{~s}^{-1}$, the $\omega=7 f$ and buoyancy $N \simeq 2 \times 10^{-3} \mathrm{~s}^{-1}$ frequencies, respectively. 
Time : 19-Jul-2003 18:00
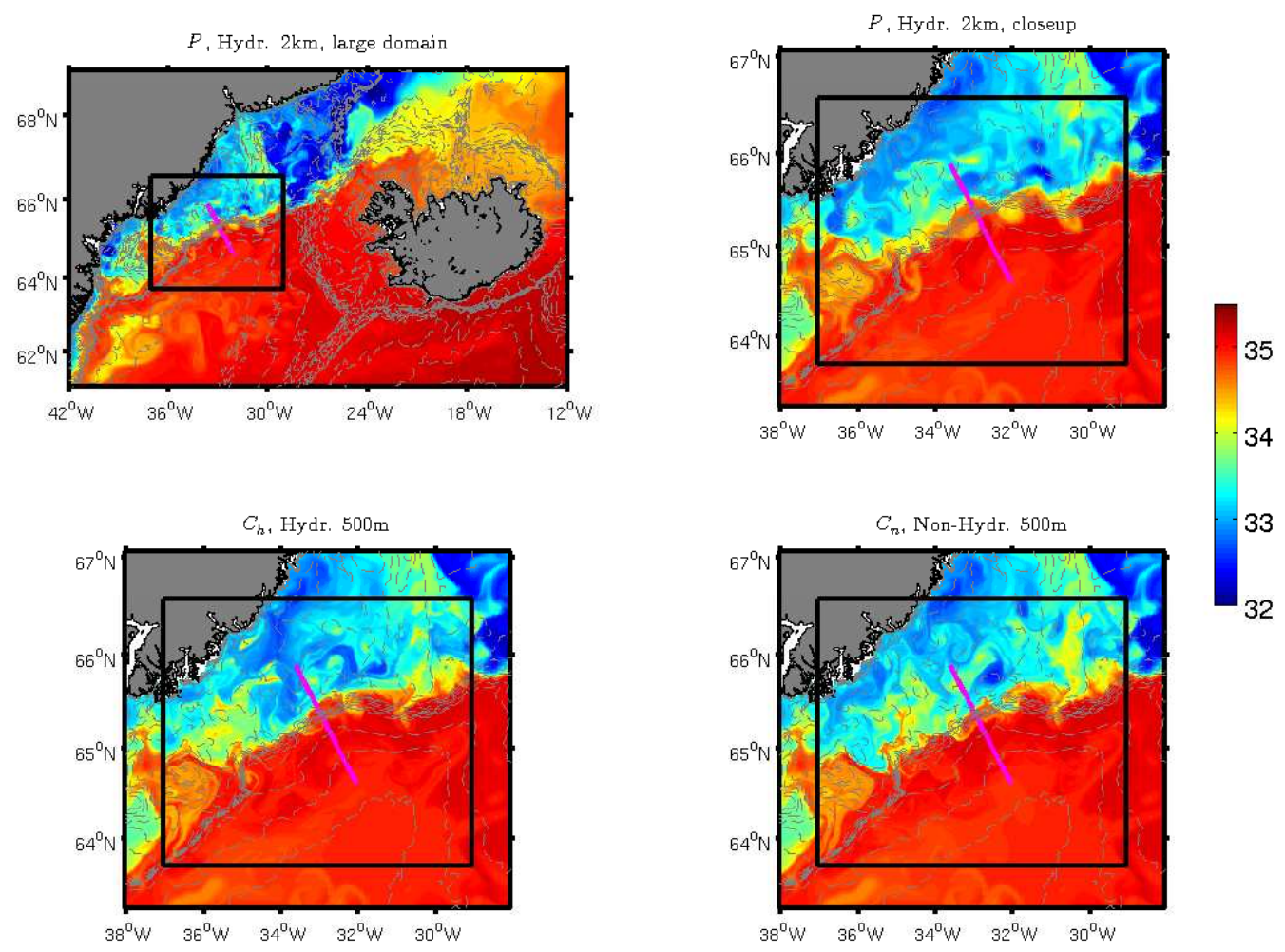

Animation 1: Evolution of the sea surface salinity in the three simulations. Top panels show the hydrostatic parent $(P)$ run, entire domain (left) and closeup (right). Bottom panels show the hydrostatic $\left(C_{h}\right.$, left) and non-hydrostatic $\left(C_{n}\right.$, right) child runs. The black box denotes the boundaries for the child grid, the Spill Jet line is in magenta and isobaths are in gray as in Fig. 1. A frame every 3 hours is shown for the child runs. A frame every 6 hours is shown for the parent run. Duration: from July 1 to September 1, 2003. 


\section{Time : 19-Jul-2003 18:00}

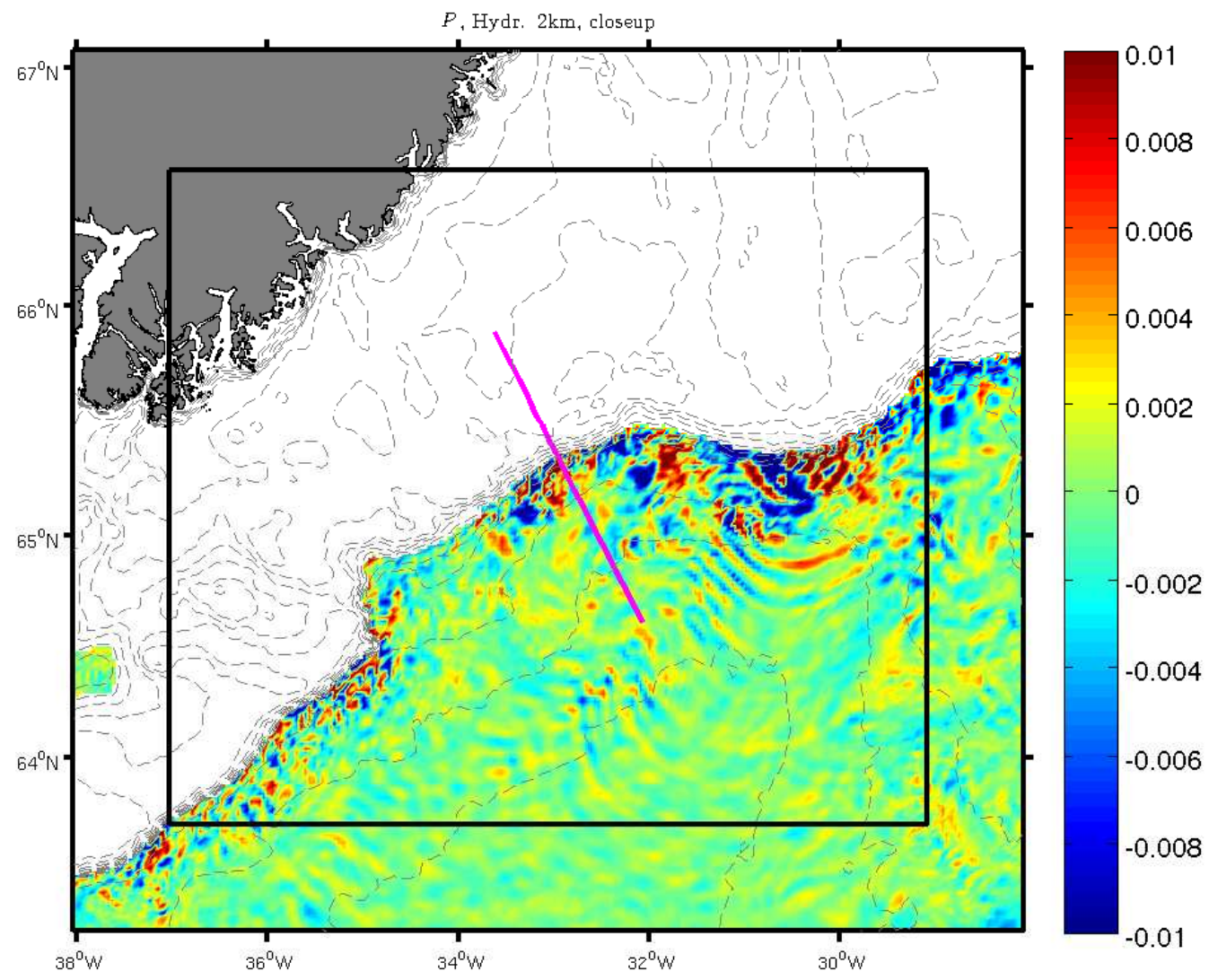

Animation 2: Evolution of the vertical velocity field in the parent $P$ run at $719 \mathrm{~m}$ depth showing evidence for IGWs. The black box denotes the boundaries for the child grid while the Spill Jet line is in magenta. A frame every 6 hours is shown. Duration: from July 1 to September 1, 2003. 